\title{
SILENCIOS GEOGRÁFICOS EN PATAGONIA-AYSÉN: TERRITORIO, NOMADISMO Y PERSPECTIVAS PARA RE-PENSAR LOS MARGENES DE LA NACION EN EL SIGLO XIX
}

ANDRÉS G. NÚÑEZa, RAÚL MOLINA O ${ }^{\mathrm{b}}$, ENRIQUE ALISTE A. ${ }^{c} \&$ ÁLVARO BELLO M. ${ }^{\circledR}$

\section{RESUMEN}

Se discute la idea y representación de espacio vacío que se construyó para la costa de PatagoniaAysén a partir del supuesto abandono de los indígenas chonos en los siglos XVIII y XIX. Para rebatir este imaginario geográfico se identifican importantes actividades y los oficios de la presencia chilota durante el siglo XIX. La ocupación de los archipiélagos, a su vez, significó la existencia de una articulación de estos espacios insulares con Chiloé, cuyo poblamiento y presencia chilota-indígena, fue la antesala y un puente que permitió la ocupación de las tierras continentales de Aysén a comienzos del siglo XX. Se concluye que aquella producción de vacío geográfico se vinculó a la necesidad de controlar esos amplios territorios desde una perspectiva centro-periferia en coherencia con el proyecto de la Modernidad. Desde esta perspectiva, los territorios estáticos, como las concesiones ganaderas, fueron visibilizados y, por el contrario, el nomadismo indígena-chilote fue -y sigue siendo- considerado un no-ser, una espacialidad asentada en los márgenes de la nación

PALABRAS CLAVE: nomadismo, centro-periferia, Patagonia-Aysén, silencios geográficos, colonialidad.

\section{GEOGRAPHICAL SILENCES IN PATAGONIA-AYSÉN: TERRITORY, NOMADISM AND PERSPECTIVES FOR RE-THINKING THE MARGINS OF CHILE IN THE NINETEENTH CENTURY}

\section{ABSTRACT}

We discuss the idea and the representation of a void which was constructed for the coast of Patagonia-Aysen after the supposed abandonment of the area by the Chonos indigenous people in the 18th and 19th centuries. We identify important activities and functions carried out by people from

a Instituto de Geografía y Estación Patagonia de Investigaciones Interdisciplinarios UC. Pontificia Universidad Católica de Chile. aanunezg@uc.cl

b Centro de Investigaciones del Hombre en el Desierto CIHDE, Universidad de Tarapacá, Observatorio Ciudadano. raul17molina@ gmail.com

c Departamento de Geografía. Universidad de Chile. ealiste@uchilefau.cl

d Centro de Estudios Indígenas e Interdisciplinarios. Universidad de la Frontera. a.bello.maldonado@ufro.cl 
Chiloe during the 19th century in order to challenge this geographical imaginary. The occupation of the archipelagos by the indigenous population of Chiloé implicated coordination of these island spaces with Chiloe Island; it paved the way for and provided a bridge to the occupation of the mainland zone of Aysén at the beginning of the twentieth century. We conclude that this production of a geographical void was linked to the need to control these extensive tracts of territory from a centre-periphery perspective which was consistent with the Modernisation project. From this perspective, the static settlement of the territories, like cattle-farming concessions, was made visible; the nomadism of the indigenous population was -and remains- considered non-existent, and the territory was considered a settled area at the margins of the country.

KEY WORDS: nomadism, centre-periphery, Patagonia-Aysen, geographic silences, colonising occupation.

\section{INTRODUCCION}

Los archipiélagos de las Guaitecas y de los

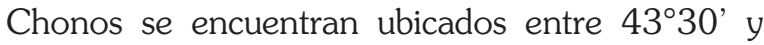
$46^{\circ} 40^{\prime}$ de latitud sur, aproximadamente entre el puerto de Melinka y la Laguna San Rafael. Este espacio patagónico, a mediados del siglo XIX, formaba parte de la provincia de Chiloé que extendía su jurisdicción austral, hasta el Cabo de Hornos (Bosquejo, 1851, p. 4). A su vez en Chiloé, la costa de payos, espacio de ocupación indígena y mayoritariamente de descendientes de chonos, formaba parte del distrito de Chonchi, desde Vilupulli hasta Cailin, donde existian 8.903 habitantes (Bosquejo, 1851, p. 6). Desde noviembre de 1885 , el puerto de Melinka, fundado en 1859, fue una subdelegación que comprendió a los archipiélagos de Guaitecas y Chonos (Schwarzenberg \& Mutizábal, 1929, p. 42), el que a principios del siglo $\mathrm{XX}$, seguía teniendo como centro de población a Melinka (Cavada, 1914, p. 9-10).

A pesar de la formalidades del poder administrativo, los archipiélagos de las Guaitecas y de los Chonos, es decir, la costa de la actual Patagonia-Aysén, fueron marcadamente desconocidos en el siglo XVIII y XIX al considerárseles como espacios vacíos $y$, en consecuencia su población, principalmente indígena, terminó siendo invisibilizada ${ }^{1}$. Así fue madurando un imaginario geográfico que ha

1 Respecto de la invisibilización del indígena y el consecuente ocultamiento étnico nos abocaremos en la parte final de esta investigación, apuntando en general a subrayar que aquello se produjo por la forzada imposición de una homogénea identidad nacional a partir del siglo XIX así como por la llevado a considerar que la memoria/historia de Patagonia-Aysén comienza en el siglo XX con la concesión y delimitación de territorios fijos y estáticos a empresas ganaderas y donde un eventual nomadismo indígena es solo un antecedente marginal del asunto. Desde la perspectiva de nuestra investigación, tal situación obedece a un asunto de fondo y tiene que ver con dos aspectos muy relevantes. Por un lado, con la comprensión de una geografía como ciencia anclada en una tradición cuyo eje de estudio ha sido el espacio objetivo, tangible, medible, visible, lo que desembocó hacia el entendimiento de un espacio ubicable, emplazable, localizable. Por otra parte, el largo dominio de discursos marcadamente centralizados, arraigados, en el fondo, en los procesos de la colonialidad del poder/saber/ser resaltada por Mignolo (2011), donde determinados territorios solo son atendibles en el ámbito de la proyección de quién los define, es decir, para el caso, de la centralidad nacional.

Desde la primera lectura, Patagonia-Aysén, hasta la actualidad, ha evidenciado interpretaciones monopolizadas por lo físico y lo (geo) político, tanto para denotar que se trata de espacios aislados, "separados" de un cuerpo central, como para resaltar su nula o reducida integración a la nación y, por lo mismo, sus altos niveles de desconexión geopolítica. Desde la segunda mirada, Patagonia-Aysén ha sido observada como un territorio marginal de la nación, no suficientemente integrado y que, por lo mismo,

también homogenización de la diversidad étnica regional bajo el gentilicio "chilote". Si lo "chilote" se asoció a la Isla Grande, su nomadismo y raíz indígena (Molina \& Correa, 1996) en Los Chonos y Guaitecas quedó reducido a "vacío geográfico". 
llegó a denominársele "tierras de entre medio" (Bandieri, 2011, p. 220), a fin de denotar la existencia de un espacio vacío entre dos cuerpos sólidos: la Nación y el territorio de Magallanes. En ambos casos, desde nuestra perspectiva se omitió -y se sigue omitiendo- la comprensión del espacio geográfico como historicidad y formación discursiva (Foucault, 1967, 1997), como producción de significados territoriales (Bourdieu, 1988), desde la lógica de la producción de imaginarios geográficos (Lindón \& Hiernaux, 2012; Lois, 2014; Zusman, 2013; Said, 2010; Núñez, 2013 a y b) o como procesos de configuración de representaciones territoriales (Aliste \& Núñez, 2015; Núñez et al. 2014 a y b), tanto desde la visión del poder (institucionalización del espacio) como desde la posición de las prácticas sociales locales. En ambos casos, el sujeto social -y su espacialidad- no es solo el Estado, es también el habitante local que se readapta y redefine a partir de un espacio geográfico reinventado y resignificado, lo que implica movilidad y cambio.

En este contexto, es relevante constatar, por tanto, como es la apuesta del presente artículo, que Patagonia-Aysén, tanto en los siglos XVIII y XIX como en el XX, incluso en la actualidad, ha sido el resorte de un imaginario geográfico de escala nacional, es decir, una (re) producción social y territorial acorde a esa lectura. Aquello llevó, como veremos, a invisibilizar una comprensión del espacio desde una perspectiva nómade $y$, por lo mismo, a silenciar y vaciar esas ocupaciones y a resaltar una espacialidad estática asociada a las concesiones ganaderas iniciadas en el siglo $\mathrm{XX}^{2}$. Los motivos para este ocultamiento no son ajenos al poder, en tanto la construcción de un imaginario geográfico de escala nacional ha sido coherente con la necesidad de incorporar e integrar diversos territorios que permanecían ajenos precisamente al control central. Así, por ejemplo, se desarrolló un imaginario geográfico para la Araucanía "salvaje" de fines del siglo XIX o en Argentina, se proyectó un "desierto" para Patagonia con el fin de denotar "espacios vacíos", invisibilizando las diversas etnias indígenas que se movilizaban por esas zonas. Otro

2 El punto es elocuente, por ejemplo, cuando en 1918 el Estado chileno envía tropas "argentinas" a reprimir ocupaciones espontáneas que, desde la perspectiva del Estado central, perjudicaban el funcionamiento del programa de concesiones ganaderas impulsado desde tanto sucedió con la cordillera de Los Andes al fijarse en ella un territorio naturalizado como barrera, lo que la ha proyectado también como espacio vacío $^{3}$. En esta misma línea, se ha proyectado y resaltado para Patagonia-Aysén una memoria que solo la vincularía a las lógicas de ocupación de una espacialidad estática, medible, cartografiable. Desde esta perspectiva, Patagonia-Aysén deviene en el siglo XIX, como en el área Argentina, en "desierto". De algún modo la movilidad indígenachilota fue ocultada y la articulación a Chiloé de estos territorios insulares sufrió igual camuflaje, de modo de erigir un espacio vacío, acorde a las políticas y el discurso de la colonización del siglo $\mathrm{XX}$, que desmereció la presencia y la agencia local, valorizando y resaltando únicamente el sentido del espacio proyectado desde una texto centroperiferia.

Para discutir la construcción del espacio vacío insular y la invisibilización de la ocupación multiétnica, principalmente indígena, este artículo lidia con los fundamentos del aparente despoblamiento chono, analiza la actividad económica en los archipiélagos, demostrando su continuidad desde el siglo XVIII, estudia los oficios, la localización de las faenas, releva la permanencia y los asentamientos y destaca la procedencia de los ocupantes. Finalmente, se plantea la pregunta acerca de la identidad étnica de los chilotes, concluyendo que ha existido una continuidad de la ocupación a cargo de indígenas descendientes de chonos y de algunos huilliches que mantuvieron y crearon nuevas territorialidades en estos archipiélagos, articulando a través de sus oficios y economía tradicional, estos espacios desde el sur de Chiloé.

La apuesta de este trabajo es, en el fondo, a re-pensar los territorios y ponderar su existencia desde una marginalidad que puede ser también una centralidad. Los nomadismos siguen estando presentes en la costa de Patagonia-Aysén y continúan siendo invisibilizados como clave para planificar u ordenar el territorio o para considerar la movilidad y la memoria local como un antecedente relevante a la hora de "imaginar" los territorios.

Santiago.

3 En un reciente trabajo (Núñez 2013a) hemos destacado numerosas investigaciones que dan cuenta de la variada movilidad andina, cuya principal característica sería más bien su condición de "bisagra" que de límite o barrera. 


\section{GUAITECAS Y CHONOS} COMO ESPACIO VACIO

Por mucho tiempo se ha proyectado al archipiélago de las Guaitecas y Chonos como una geografía despoblada. Un lugar que se transformó en un aparente espacio vacío en la segunda mitad del siglo XVIII, luego del abandono de los Chonos de estos paisajes insulares. Se explicó la desocupación por el repliegue del poblamiento indígena a los canales al sur del Istmo de Ofqui y la migración indígena a Chiloé, donde habrían partido tras dar por terminada las guerras de malocas contra las islas de Chiloé (Olguín, 1981; Urbina, 1988). El filólogo Jorge Ibar Bruce escribió: Los chonos constituyen una raza fenecida. A través de la historia sabemos que desaparecieron a fines del siglo XVIII en parte refundidos con los habitantes de Chiloé (huilliches) y en parte, por su emigración al sur del istmo de Ofqui (Ibar Bruce, 1960, p. 61). Otros autores indican que en siglo XIX los chonos ya no están en sus laberintos insulares (Urbina, 2007, p. 326). Ambos textos no admiten la continuidad del poblamiento de estos archipiélagos, más bien se difunde la idea del abandono y la soledad, quedando un hiato despoblado entre Chiloé y los canales más al sur de la Península del Taitao.

Durante las primeras décadas del siglo XIX, Charles Darwin reforzará la imagen de espacio vacío de los archipiélagos. Su prestigio intelectual actuará de modo omnipresente respecto de ciertas apreciaciones de los paisajes australes. En 1834 en su viaje por Chiloé y el archipiélago de los Chonos, permanece tres días en las Islas Guaitecas arreciado por el mal tiempo, escribiendo su visión desoladora de las costas y, en cuanto a la tierra, (que compara con Tierra del Fuego)... está cubierta de bosques tan espesas que todos mostramos..., las huellas de los esfuerzos que hicimos para penetrar en sus soledades (Darwin, 1945, p. 338). De la misma opinión es Fitz Roy: En cuanto a los nombres nativos, dados por los indios, no tenía los medios para averiguarlos pues no se vieron habitantes (Fitz Roy, 2013, p.

4 A fines del siglo XIX las apreciaciones de Darwin y Fitz Roy merecerán la crítica de Vidal Gormaz: Se han mirado con desdén inconsciente estos archipiélagos... que las apreciaciones de los viajeros ilustres como el
$321)^{4}$. Se fijaba así, un imaginario de soledad en la naturaleza y despoblamiento indígena.

Pareciera que a los navegantes de Chiloé -denominados por el gentilicio chilotes-, que Fitz Roy encuentra en 1834 en el puerto Low, a la entrada de las Guaitecas y de camino a los canales del sur en busca de lobos y nutrias, no son considerados pobladores temporales $\mathrm{y} / \mathrm{o}$ estacionales de las islas, y menos se les identifica como indígenas. Más bien su presencia se consideraba un incidente, algo eventual, una estadía fortuita, sin relevancia. La idea de soledad y vacío continúa vigente a fines del siglo XIX cuando se describía al archipiélago de los Chonos como un gran conjunto de islas grandes y pequeñas, extremadamente boscosas, todas ellas, agrestes, deshabitadas casi en absoluto, aunque pobladas accidentalmente por los madereros en verano (Vidal, 1905, p. 6). Estas descripciones ayudaron a fijar un horizonte de comprensión para los archipiélagos de Chonos $e$ islas Guaitecas como espacios aparentemente deshabitados, al desestimar la existencia de un poblamiento temporal, nómade y estacional más sistemático, articulado económicamente desde Chiloé. En efecto, cuando se interrogan las evidencias del poblamiento y la actividad económica en estos espacios insulares, aparece "lo chilote" como categoría genérica del poblamiento insular, y "lo indígena" queda subsumido como identidad, que continuó poblando estos espacios insulares. El nomadismo como expresión geográfica, por tanto, es recurrentemente invisibilizado.

Sin embargo, el imaginario geográfico de tipo solitario de los archipiélagos de las Guaitecas y de los Chonos, se esfuma gradualmente al subrayar las actividades económicas que se desplegaron en esta zona durante el siglo XIX, donde el poblamiento chilote-indígena estuvo asociado a las actividades tradicionales como la caza, la pesca, la recolección marina y la crianza de ganado en diversas islas y, después de 1850, a la explotación ampliada del ciprés de las Guaitecas. Además de la población chilota-indígena, se contará con la presencia de chilotes criollos y extranjeros, que aprovechan los abundantes recursos de estos archipiélagos. Estos

almirante Fitz-Roy, Darwin y otros, que no pudieron darse cuenta de la importancia de aquella región insular, que estudiaron muy a la ligera (Vidal, 1905, pp. 12-13). 
últimos serán, entre otros, loberos, balleneros, explotadores del ciprés, industriales conserveros de mariscos y extractores de hielo del glaciar de San Rafael (Simpson, 1871, 1872, 1874; Guillermos, 1901; Vidal, 1905; Martinic, 2005; Torrejón et al. 2013). En ellos también existe una geografía nómade que ha sido minimizada desde aquella condición.

A los chilotes-indígenas, la permanencia temporal o constante en estos archipiélagos les otorgará un afinado conocimiento de la geografía física, del territorio y de la navegación por estos espacios insulares, siendo requeridos como prácticos para acompañar a expediciones científicas desde mediados del siglo XVIII hasta fines del siglo XIX, desde el viaje del Padre José García (1889) hasta Enrique Simpson (1871, 1872, 1874) y Hans Steffen (1910). Este conocimiento geográfico incluirá la noción de los escasos puertos y playas de recaladas. José de Moraleda, observa esta particularidad: Es tal la escases o penuria de atracaderos en todo este archipiélago que precisa a llamar puerto a cualquiera pequeña playa de arena o lastre que se presenta, i aunque para saltar en ellas hai que vencer obstáculos, riesgos i atrasar la navegación (Moraleda, 1888, p. 317).

La discrecionalidad de los puertos y playas, generará una constante ocupación y reocupación de los más conocidos, encontrándose en muchos de ellos una estratigrafía del poblamiento, cuya expresión más pretérita serán los conchales arqueológicos (Simpson, 1871, 1874; Flores \& Lira, 2006; Reyes et al. 2007, 2009, 2011). La sucesión de las ocupaciones se puede apreciar en la fundación de Melinka en 1859. Al abrirse los terrenos, aparecen las evidencias del asentamiento histórico: se hallaron en él muestras de antiguos cultivos y también hachas de piedra de las que usaban los antiguos indios payos, puntas de flecha y aún platos de madera de ciprés de que se servían y que todavía están en uso en el sur de Chiloé (Vidal, 1905, p. 5). Probablemente estos restos correspondían a la misión jesuítica en la isla Vielaiguai, actual isla del puerto de Melinka: Paró esta misión con la muerte de un cacique chono buen cristiano, que la procuraba. (García, 1889, pp. 40-41). Este puerto compartía sus características con el abrigado puerto Low, uno de los mejores de aquellas desoladas costas
(Vidal, 1905, p. 5). Por ello, nombres como Low, Melinka, Tangbac, Lagunas o Traiguén, entre otros tantos, serán topónimos que se repetirán en los relatos y testimonios de la ocupación del siglo XIX. Estos lugares serán usados de resguardo, de paso o de asentamiento en el desarrollo de sus actividades económicas, vinculadas al aprovechamiento de los recursos marinos y del bosque, y a las actividades agrícolas y ganaderas. En esos puertos y playas, se asentarán frecuentemente pescadores, loberos y hacheros chilotes que mantendrán una sucesiva ocupación histórica, desmintiéndose así la idea de espacio vacío que se forjó por la tradición de una memoria geográfica anclada en la visibilización de lo estático y por la necesidad de contar con espacios despoblados para justificar su incorporación a la nación.

\section{ECONOMIA DE LOS ARCHIPIELAGOS EN EL SIGLO XIX}

En el siglo XIX el archipiélago de las Guaitecas y de los Chonos fue ocupado económicamente por actividades productivas tradicionales y de explotación industrial. El primer modo productivo incluye la pesca, la recolección, la caza marina y la ganadería en pequeñas islas, todas actividades que articularon económicamente a Chiloé con los archipiélagos de más al sur, como parte de sus economías de subsistencia y de abastecimiento de mercado locales. El segundo modo productivo fue el industrial, una explotación centrada en la caza de lobos, en las conserveras de mariscos y en la explotación del ciprés. Las geografías insulares fueron caracterizadas a modo general por su economía basada en la pesca y la explotación de maderas (Bosquejo, 1851, p. 25) que ofrece abundante pesquería, mariscos variados y en grandes cantidades, excelentes maderas de construcción, como ciprés, roble, muermo, tepú, laurel, varias clases de mañius, canelo, teñiu y varias otras que sería prolijo enumerar (Vidal, 1905, p. 7). También, por la explotación del huano, pescado seco, aceite y cueros de lobos (Simpson, 1871, p. 196), donde además indígenas de Chiloé, solían mantener ganado y realizaban reducidos intentos de agricultura en estas islas, todo lo que, en definitiva, será un continium territorial en los inicios del 
siglo XX (Cavada, 1914, p. 44) e incluso hasta la actualidad, dada la movilidad identificada en diversas actividades costeras.

La caza de lobos marinos era una práctica tradicional entre los chonos (Beranger, 1893; Vea, 1886), la que continuó en el siglo XIX, incluyendo entre las especies cazadas al lobo marino común (Otaria flavescens) y al elefante marino (Mirounga leonina). Pero fue la caza industrial, de loberos ingleses y norteamericanos, la que generó una sobreexplotación y la extinción local del elefante marino y la foca leopardo (Hydrurga leptonyx) y puso en peligro el lobo de dos pelos (Arctocephalus australis) (Albert, 1901; Torrejón et al. 2013). Estas especies fueron cazadas sin limites durante la mayor parte del siglo XIX, pues su explotación sólo fue regulada en 1883 y $1892^{5}$. El interés de la caza industrial estuvo en los buenos precios de los cueros, en los aceites de mejor calidad que el de ballenas -más suave y con menos olor- y en las lenguas ahumadas, que se exportaban a Europa (Albert, 1901).

Por su parte, la caza de lobos entre los indígenas era una práctica ancestral destinada a obtener carne, cueros y aceite. En el viaje de 1766 el Padre José García, acompañado por 48 caucahues o chonos, residentes en la isla Cailin del sur de Chiloé, al pasar a la cuadra de la isla Guiguai, cercana a las Guaitecas, escribe dimos vista a unos peñascos llenos de lobos marinos; luego los caucahues con inexplicable gusto enderezaron la proa para la lobería $i$ desarbondando la piragua con mucho silencio $i$ con su suave rema se fueron acercando... lograron matar once, $i$ algunos como terneros (García, 1889, p. 6). Esta práctica será frecuente, pues a fines del siglo XVIII continúa por los indios guaihuenes de Chaulinec i Cailin, (Archipiélago de Chiloé) que anualmente viene a estas islas a la pesca de lobos para grasa, i también a veces para sustento (Moraleda, 1888, pp. 324325). La tradición de la caza no cesará en el siglo XIX. En 1834, Fitz Roy advierte que en puerto

5 Debido a la sobrexplotación y extinción de especies de lobos marinos el Ministerio de Relaciones Esteriores Culto $i$ Colonización...nombró el 16 de Marzo de 1883 una comisión compuesta de los señores Oscar Viel capitán de navio Alfredo von Rodt i H Houland a fin de que presentara al Ministerio un proyecto de reglamento de la
Low, cerca de Melinka que algunas piraguas de Chiloé estaban en el puerto: en ellas se hallaban los chilotes en busca de lobos de río, focas, y nutrias, habian atravesado el golfo de Huafo, en sus navios mal acondicionados, con poca trepidación (Fitz Roy, 2013, p. 327). Esta explotación económica es posible encontrarla a lo largo del siglo XIX y se proyecta en el siglo XX. Según Emperaire (2002), la caza de lobos en los canales australes, tuvo su mayor auge entre 1890 y 1914, pero estas no se extinguieron hasta la década del cincuenta en el siglo XX.

La economía de la caza de lobos implicó la extinción local de algunas especies: La punta Elefantes... (fue) frecuentada en tiempos pasados por raza enorme de focas marinas, que luego fue esterminada por los loberos... existía además otra raza de focas, mayor que los lobos comunes, pero menor que los elefantes; las denominadas leopardos por ser pintadas de manchas negras (Simpson, 1871, 177). La extinción local de estas dos especies, no solo podría ser adjudicada a los loberos chilotes, sino especialmente a la caza industrial pues desde Inglaterra i los Estados Unidos venían las embarcaciones provistas de los víveres necesarios i tripuladas convenientemente para esplorar las loberías del país (Albert, 1901, p. 903). En 1843, el bergantín goleta americana Enterprise de Stonington, ... hacía 10 meses se ocupaba en la pesca de lobos (Guillermos, 1901, pp. 16-17) y, junto a este, actuaba la goleta Betzei, de Nuevo Lóndres, su capitán Perkins, loberos ámbos (Guillermos, 1901, p. 19). En la década de 1870 continuaba este tipo de faenas extranjeras, pues el puerto de Melinka, era frecuentado por estos loberos, como un lobero americano llamado Mike, que en el verano había estado con su goleta (Simpson, 1874, p. 528). El incentivo económico era el beneficio grande que se obtiene de los elefantes marinos ha llamado muchas empresas para esplotarlos $i$ asi ha sucedido que los abundantes rebaños

pesca i caza de lobos en las aguas territoriales del Estrecho i canales de Magallanes. ... (pero) impunemente se podian violar las medidas...i al fin se puso término a la esplotación imprudente por medio de la siguiente ordenanza del Ministerio de Industria que fue dictada en Santiago el 17 de Agosto de 1892 (Albert, 1901, pp. 902-903). 
que existian antes en nuestras costas desde el territorio de Magallanes hasta el limite norte han desaparecido. Todavía en el primer decenio del siglo pasado se han muerto cerca de 40,000 ejemplares en la costa de la Patagonia pero en la mitad del siglo se los ha esterminado por completo (Albert, 1901, p. 885). En el caso de los lobos de dos pelos el mayor beneficio consiste en la venta de los cueros i de importancia secundaria es la producción del aceite de lobo. Los cueros eran exportados y servían para fabricar sombreros, guarniciones de vestidos y capas para señoras... y se pagaban en el Territorio de Magallanes, por partidas grandes sin distinción de tamaño a razón de dieciocho a veinte pesos (Albert, 1901, p. 900). Cuando la caza industrial de lobos marinos declinó a fines del siglo XIX, ésta continuó siendo efectuada por chilotes, en su mayoría indígenas.

En el caso de la pesca, esta es una actividad económica recurrente en los archipiélagos de Guaitecas y Chonos. En el siglo XIX servía a la subsistencia y alimentaba el comercio de los archipiélagos, siendo desarrollada tradicionalmente por los indígenas y otros chilotes. Se cogían preferentemente robalos, congrios y bacalao con técnica de corral, anzuelo y redes, técnicas que perduran hasta el día de hoy. El corral era usado para la pesca de robalos: el modo de pescar es el siguiente (igual que el del archipiélago de Chiloé): siendo el robalo mui abundante en la boca de los riachuelos, en donde el agua es casi dulce, se hace, en el banco frente a estos, un corral compuesto por estacas y ramas, dejándose una puerta ancha por donde el pescado pueda entrar. Esta se cierra en alta marea, de modo que cuando bajan las aguas, queda el pescado encerrado i se toma a mano. De este modo en Lagunas (cerca del estuario de Aysén) los pescadores del buque cojieron en una sola marea más de 1.700 robalos. Este pescado por lo regular se sala i se ahuma, $i$ tiene buen mercado en Chiloé, especialmente en la cuaresma. (Simpson, 1872, p. 418). Es decir, el pescado es elaborado como charqui o pescado ahumado, para ser guardado o vendido en los mercados locales de las islas del archipiélago de Chiloé.

Otra actividad económica relevante en los archipiélagos de Guaitecas y Chonos fue la ganadería (Tabla 1), que tiene un sello indígena en estas islas e

Tabla 1. Algunas ocupaciones ganaderas en las Islas de Guaitecas y Chonos.

\begin{tabular}{ccccc}
\hline Isla & Nombre actual & Ganado & Año & Referencia \\
\hline Calserau & Boca estuario Aysén & Caprino & 1766 & José García \\
Caicaiyenec & Boca estuario Aysén & Ovino & 1766 & José García \\
Iquilao & $\mathrm{S} / \mathrm{i}$ & Caprino y ovino & & Moraleda \\
Quimanec & $\mathrm{S} / \mathrm{i}$ & Caprino y ovino & & Moraleda \\
Ayoupa & $\mathrm{S} / \mathrm{i}$ & Caprino y ovino & & Moraleda \\
Menchuan & $\mathrm{S} / \mathrm{i}$ & Caprino y ovino & & Moraleda \\
Meñan (Inchemó) & Inchemo o Mañauque & Caprino y ovino & & Moraleda \\
Setucápel & $\mathrm{S} / \mathrm{i}$ & Caprino y ovino & & Moraleda \\
Huamblin & Huamblin & Caprino y ovino & 1834 & Fitz Roy \\
Ipun (Nalborough) & Ipun & Caprino y ovino & 1834 & Fitz Roy \\
Lemu & $\mathrm{S} / \mathrm{i}$ & Caprino y ovino & 1834 & Fitz Roy \\
Huafo & Huafo & Ovino & 1834 & Fitz Roy \\
Inche & Inche & Caprino & 1870 & Vidal Gormaz \\
Tenquehuen & Tenquehuen & Caprino & 1870 & Vidal Gormaz \\
Melinka & Guaiteca & Ovino, porcino, caprino & 1870 & Vidal Gormaz \\
\hline
\end{tabular}


implementado en el periodo colonial. La ganadería fue primero realizada por los chonos y luego por el chilote-indígena o sus descendientes. Se trata de la crianza libre de caprinos y ovinos que se dejaban en islas con vegetación arbustiva y pastos y de no muy extensas superficie, donde se les visitaba una o dos veces en el año. La crianza ganadera en estas islas se remonta a lo menos al siglo XVIII, cuando los caucahues o chonos radicados en la isla Cailin, ubicada al sur de Quellón, tenían un importante número de ganado caprino y ovino en las islas Calserau y Caicayenec, cercanas al estuario de Aysén: en la isla Calserau dimos fondo con el fin de coger cabras de las que en dicha isla tenía un caucahue (García, 1889, p. 10) agregando que a su regreso de su viaje, Proseguimos, i cojiendo en la isla Calserau su dueño una cabra $i$ un cabrito, i en la isla Caicayenec, oveja, fuimos a alojar a la grande isla Melenguen que tiene buenos pedazos de tierra para cultivar (García, 1889, pp. 38-39). Se agregan como potreros de crianza de animales, las islas Huamblin, Ipun (Narborough) y Lemu, citadas por Fitz Roy (2013, p. 321), donde los indios chonos poseían pequeñas rebaños de cabras y ovejas. Al parecer los indígenas de la Isla Cailin y Chaulinec tenían un archipiélago ganadero formado por varias islas, a la que se suma la isla Huafo, donde No hay ahora habitantes en esa isla, aunque si muchas ovejas que pertenecen a los chilotes, que viven en Caylin. Antes había indios en Huafo, llamados huyhuenche (Chonos) (Fitz Roy, 2013, p. 329). También, el ganado ovino y caprino fue muy abundante en las islas Inche y Tenquehue, en la entrada occidental del canal Pulluche (Entre las actuales islas Salas y Riveros) pero a fines de la década de 1870 escaseaba debido a la caza inmoderada á que se dedicaron los tripulantes de las embarcaciones pescadoras y algunos otras pocos años después de haberse abandonado en esas islas las referidas cabras... y serian muy abundante si no la codiciasen tanto los

6 Enrique Simpson en la década de 1870 intenta poblar remotos lugares de los archipiélagos con ganado: Aquí hice desembarcar (en la boca del río Huemules, cerca del canal costa) los terneros que había traído $i$ también dos parejas de gallo y gallinas, con el objeto de dejarlos propagar ahí (Simpson, 1874, p. 524). Días después el mismo vuelve a acampar a la boca del río Huemules, encontrando sanos y gordos, pero ya habian perdido mucho de su mansedumbre, pues cargaban al aproximárseles Advirtiendo que El único peligro el que loberos (Vidal, 1905, p. 9).

Como señala Fitz Roy (2013) y Vidal Gormaz (1905) en el siglo XIX, la ganadería ovina y caprina era una actividad ligada a los chilotes, especialmente de la Isla Cailin y Chaulinec, que constituye uno de los reductos de los antiguos chonos, radicados en el siglo XVIII en estas islas del sur de Chiloé. Estos mismos habitantes, a fines del siglo XVIII se dirigían a las islas a sacar el sebo i hacer charqui del ganado lanar i cabrío, que tiene en algunas vecinas a Inchemó, estremo sur i oeste del archipiélago (Moraleda, 1888, pp. 324325), actividades de aprovechamiento ganadero, que seguramente continuaron durante todo el siglo decimonónico. Lo señalado está demostrando una continuidad en el uso ganadero de los archipiélagos de Guaitecas y de los Chonos, modelo productivo que será adoptado por los exploradores chilenos, que a fines del siglo XIX comenzaban a pensar en el poblamiento y colonización del Aysén continental ${ }^{6}$.

Los cultivos agrícolas de papas y a huertos de manzanos fueron intentos más escasos y con menos resultados, que tenían netamente un fin de subsistencia. Los huertos de manzanos que ya existían a fines del siglo XVIII, fueron plantados por indígenas que visitaban o habitaban estas islas de Guaitecas y Chonos. José de Moraleda encuentra en la Isla Tanhao (Tangbac) 20 manzanos unidos que parecen de 2 años de edad, con escaso fruto, sin duda plantados en orden por alguno de los indios guaihuenes de Chaulinec i Cailin, que anualmente viene a estas islas (Moraleda, 1888, pp. 324-325). En 1843, este lugar, se reconocía como punta Manzanos, denominada así por los árboles de ese fruto que existían allí (Guillermos, 1901, p. 17). Los cultivos advierten de una agricultura escasa, pero a la vez temprana en estos archipiélagos. Los cultivos de manzanos se encontraban en varias islas, por ejemplo en 1878 , en las Guaitecas se observaba que algunas

los maten algunos pescadores que suelen frecuentar esta playa (Simpson, 1874, p. 529). Para evitar este peligro, ordena que los arreen tierra adentro y hace correr la voz que pertenecen al gobierno, por el respeto que le tienen. De este modo es posible que en algunos años se encuentre en este valle una cantidad considerable de ganado, como sucede en el Palena $i$ en Tictoc, donde fue introducido años há, alcanzando hasta penetrar al oriente, donde los cazan los tehuelches (Simpson, p. 1874, p. 529). 
de las islas se encuentran viejos manzanos que atestiguan haber existido familias radicadas en esos puntos, y en el caso de la papa nativa, estas crecen espontáneamente en lugares, que suelen abandonar los labradores de madera $y$ los pescadores (Vidal, 1905, p. 4). Mientras a los indígenas del siglo XVIII y chilotes del siglo XIX, se les relacionaba con cultivos de papas y plantación manzanos, en los asentamientos industriales, como isla Tangbac y Melinka, se intentaban el ensayo de cultivos exóticos. En la isla Tangbac, sede de una conservera de mariscos, sus dueños en el pequeño retazo cultivado se habian cosechado mui buenos rabanos, sanahorias, coles, cebollines $i$ otras legumbres, de semillas obtenidas de Melipulli (Simpson, 1874, p. 521). En Melinka ocurría algo similar con los cultivos experimentándose con nuevas semillas importadas o traídas de Melipulli. Es destacable para comprender la continuidad de la ocupación, la existencia de una agricultura de papas y manzanos asociada al poblamiento itinerante o permanente de algunas islas, asociado a indígenas y chilotes.

Por otra parte, la economía del ciprés fue la más intensa durante la segunda mitad del siglo XIX en los archipiélagos de Guaitecas y de los Chonos (Tabla 2). Esta a los menos, se expresó en tres fases diferentes. La primera, es la explotación tradicional indígena-chilota, una segunda es la exportación de durmientes del ferrocarril y la tercera es la producción y exportación de postes para viñedos. En los tres fases lo principales trabajadores serán los chilotes, en su mayoría indígenas.

El uso del ciprés en el periodo colonial al parecer estuvo asociado a las construcciones de muebles, viviendas y corrales. Los indígenas de la isla Cailin ya lo explotaban en la isla San Pedro, pues en 1793, José de Moraleda encuentra que en las faldas orientales de la elevada montaña que forma la isla he advertido algunas quemazones o rozados de monte que no había cuando estuve en ella el año 87, sin duda hechas posteriormente para facilitar el tránsito o la saca de madera de ciprés, de que dicen abunda en esta isla (Moraleda, 1888, p. 308). Esta observación anuncia el método de explotación del ciprés que se extenderá en las Guaitecas y Chonos, basado en la quema o roce de bosques. La segunda fase, más intensa, fue la explotación del ciprés en la segunda mitad del siglo XIX, destinada a la elaboración de durmientes para exportación al ferrocarril de Callao a Lima en Perú (El Divisadero 6-11-2008), la que fue favorecida por la autorización para la explotación de bosques fiscales, que en la zona de los archipiélagos (Torrejón et al. 2013).

La fundación del puerto de Melinka en 1857 tiene el objetivo de articular el comercio de la madera de los archipiélagos de las Guaitecas y de los Chonos (Vidal, 1905)7. La explotación del ciprés fue un negocio del fundador de Melinka, el señor Weskoff, quien llego de Lima, Perú, a

Tabla 2. Algunos lugares de trabajo del ciprés por hacheros.

\begin{tabular}{ccc}
\hline Lugaar con faenas & Actividad & Autor \\
\hline Estuario Aau & Hacheros trabajando más de tres meses & Simpson, 1872 \\
Canal Pulluche & Hacheros & Simpson, 1872 \\
Canal Uturupa & Hacheros & Simpson, 1872 \\
Estero Albano & Balandra cortando madera & Simpson, 1872 \\
Estuario Puelma & Hacheros & Simpson, 1872 \\
Puerto Barcelo, Carta Hudson & Hacheros & Simpson, 1872 \\
Estero Queulat & Hacheros & Simpson, 1872-1874 \\
Canal Agüea o Darwin & Incendio de cipresal & Simpson, 1874 \\
Canal Pangal & Hacheros en cipresal & Simpson, 1874 \\
\hline
\end{tabular}

7 El puerto Melinka fue fundado para apoyar la explotación de las maderas y la pesca y caza de lobos marinos en 1852. Ese pequeño enclave a 1877 había crecido considerablemente y varias familias se habían asentado de modo permanente, tenía terrenos abiertos a la agricultura donde se cultivaban diversas hortalizas. Lo mismo ocurría con la crianza de ganado lanar, porcino, cabrío y bovino (Vidal, 1905). 
promover la explotación de estos bosques. La demanda de maderas incrementó el poblamiento temporal y estacional con hacheros provenientes de Chiloé, y en la década de 1870 se emplean más de tres mil hombres en estas faenas, esportándose anualmente unos 300.000 durmientes (Simpson, 1871, p. 196). Los hacheros se distribuían en una amplia área geográfica del archipiélago de los Chonos y en 1872 el cirujano de la Corbeta Chacabuco que estuvo tres meses en el puerto Lagunas (frente el fiordo de Aysén), atendió a varios de los cortadores de madera esparcidos en las diferentes partes de la Guaitecas i Chonos (Pendavis, 1872, p. 451). La huella de la explotación del ciprés era evidente y desastrosa (Torrejon et al. 2013), pues para acceder hasta los rodales se incineraban los bosques y las islas explotadas eran reconocidas por un paisaje de quemas al sur del Canal de Moraleda, otra práctica en uso hasta hace pocos años atrás. Así, en Queulat, al sur de Aysén, existen evidencias de haber sido quemada en época reciente (Simpson, 1874, p. 510) y en la isla Traiguen, vi con indignación que el monte había sido quemado recientemente... (y hay otras)... quemas por la carrera del Pangal, es decir, por el canal de Agüea (Simpson, 1874, p. 523). Estos últimos incendios duraron varios días y la huella del humo era apreciable desde Río Cisnes, era una nube oscura que avanzaba desde el sur, cubriendo el horizonte... Este humo,... supe, provenía del incendio de una isla por el canal Agüea, distante no menos de 70 millas de nosotros (Simpson, 1874, pp. 516-517). La corta de ciprés, también se reporta para el Puerto Barceló de Hudson, cerca del estuario Puelma, donde encontramos fondeada una balandra de Chiloé cortando maderas (Simpson, 1872, p. 411). En el estuario Aau los hacheros llevan tres meses trabajando y en el Estero Albano, del mapa de Hudson, volvimos a encontrar más hacheros (Simpson, 1872, p. 412), todos los cuales estaban produciendo en su mayor parte durmientes.

La producción maderera de las islas se acopiaba en Puerto Lagunas, cercano a la entrada sur del Canal de Moraleda y en la latitud del estero de Aysén, donde en 1874 existe un depósito de durmientes de ferrocarril (Simpson, 1871, p. 194). El otro acopio estaba en Melinka, donde se esperaba el arribo de buques a cargar durmientes... traídos por balandras desde el sur, los cuales arrumados en la playa i vistos desde lejos, dan a este lugar el aspecto de un pueblo (Simpson, 1874, p. 507). La explotación del ciprés para durmientes, comenzó a decaer a fines del siglo XIX (Torrejón et al. 2013), debido a la disminución de los rodales de esta especie en las islas y la reducción de la demanda para los ferrocarriles.

La tercera fase de explotación del ciprés, sin duda más conocida, es la emprendida por el comerciante de Chonchi, Chiloé, Ciriaco Álvarez, quién se aboca al corte de ciprés para viñedos chilenos y peruanos. En 1880 fundó en río Álvarez, entre Puerto Aysén y Chacabuco, una estación de almacenaje de postes, con casas y galpones, además de un almacén abastecedor de viveres para sus trabajadores (Peri, 1989, p. 90). Este empresario siguió su actividad hasta el siglo $\mathrm{XX}$, enrolando a chilotes y a chilotes indígenas en el trabajo de explotación del ciprés, extrayendo un ciprés más pequeño y delgado para postes de viñas. Se desconoce por ahora si hubo otras formas de trabajo del ciprés, pero si se sabe que su explotación contribuyó, no solo a incrementar el poblamiento temporal, sino también a aumentar la articulación económica entre Chiloé y los archipiélagos de las Guaitecas y de los Chonos.

En definitiva, la economía tradicional de estos espacios insulares de la costa de PatagoniaAysén se caracterizó en el siglo XIX por una activa y diversa actividad productiva, dada por el ejercicio de la caza, la recolección y la pesca marina y las actividades silvoagropecuarias, además de la explotación del ciprés a partir de 1850 (Fig. 1). Será la economía tradicional, nómade y móvil, la que sobrevivió al siglo decimonónico, puesto que en 1910 Melinka era el principal punto de embarque para los productos de la pesquería, ostras, erizos y mariscos que se practican en las costas vecinas y que atrae flotillas de chilotes con sus familias. El número de esta población nómade que recorre las islas y costas de tierra firme por regla general sólo 6 o 8 meses al año, podemos calcularlo en 600 por término medio para todo el archipiélago de las Guaitecas y Chonos (Peri, 1989, p. 198). En efecto, las actividades de corta de madera, la caza, la pesca, la ganadería se mantendrá preferentemente realizada 

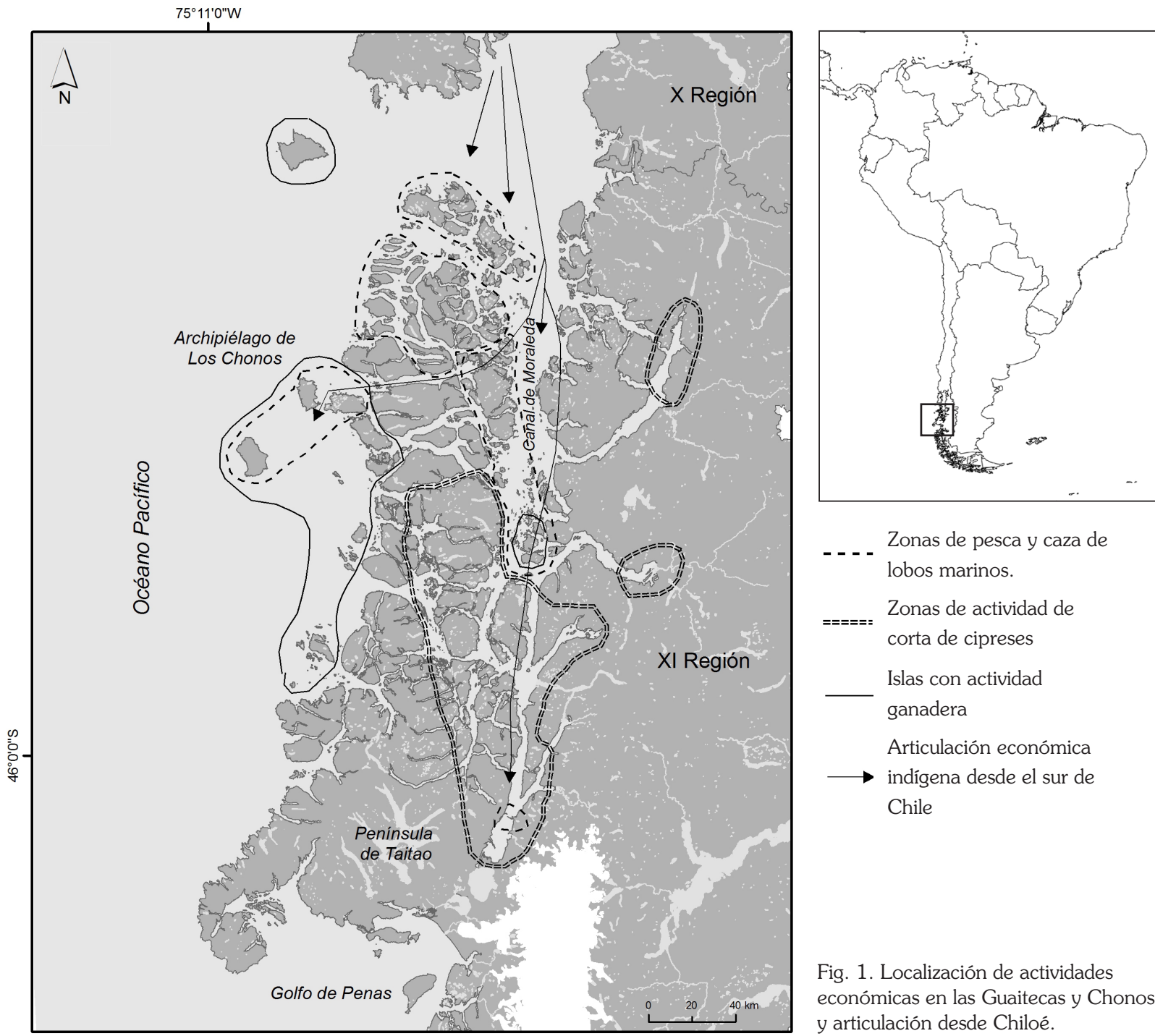

_. . . Zonas de pesca y caza de lobos marinos.

====-: Zonas de actividad de corta de cipreses

Islas con actividad ganadera

Articulación económica

$\longrightarrow$ indígena desde el sur de Chile

Fig. 1. Localización de actividades económicas en las Guaitecas y Chonos y articulación desde Chiloé.

por los chilotes, cuyos oficios de hacheros, loberos, labradores y pescadores les permitirá seguir ocupando temporal o estacionalmente esta vasta área costera, articulando económicamente los archipiélagos de Chiloé con los de Guaitecas y Chonos al concurrir cada año a estas zonas insulares, quizás reproduciendo antiguas prácticas indígenas.

Es relevante resaltar que muchas de estas prácticas perduran hasta el día de hoy: algueros, pescadores, madereros, entre otros, continúan movilizándose en una geografía social caracterizada precisamente por el nomadismo y la temporalidad.

\section{OFICIOS, CALENDARIO PRODUCTIVO Y PROCEDENCIA}

En el mismo sentido del trasfondo económico de una activa geografía social identificable para Patagonia-Aysén, los oficios nos muestran un significado del espacio marcado por el nomadismo y la movilidad. Destacamos acá los trabajos de hachero, lobero, pescador y ganadero, los cuales involucran trabajo físico o manual practicado por los chilotes, durante ciertas temporadas del año, procediendo la mayoría de los hombres desde la parte sur del archipiélago de Chiloé.

El oficio de lobero es uno de los más antiguos 
practicados en las islas Guaitecas y de los Chonos. El Padre García en 1766, escribe i a distancia de casi una cuadra pararon, i desnudos algunos caucahues, se previnieron de lazo i un palo de ocho a nueve palmos de largo que aseguraron al cuello para que no les embarazase el poder nadar, i luego poco a poco se descolgaron al mar i nadando tiraron hacia los lobos; i aunque éstos los veían no se espantaban, teniéndolos por lobos i de su misma especie; al llegar a la orilla se repartieron, i saliendo cada uno por su parte, enarbolando el palo i acomentieron a los lobos (García, 1889, p. 6). Esta audacia no estaba exenta de peligros y graves accidentes, pero la caza del lobo marino aportaba aceite doméstico, cueros para la talabartería y los trabajo artesanales, como correajes y aperos de pesca y agricultura. El oficio de lobero ocurría durante las pariciones en esta época es sumamente fácil matar los padres, i como expreso un viejo lobero: ¿Para qué dejar los cachorros cuando solos se morirían sin las madres? El mismo individuo me contó que en una sola estación había muerto más de 3.000 cachorros (Simpson, 1871, p. 177). Según un antiguo cacique de Compu, Chiloé, don José Santos Lincomán, todos los loberos de costa de Payos, de Queilen a Quellón e isla cercanas, viajaban en sus embarcaciones a las Guaitecas y al archipiélago de los Chonos en los tiempos de la lobada, meses de enero y febrero (Lincomán, 1990 , p. 82), ello a pesar que los torunos están más gordos en Octubre i más flacos en Marzo (Albert, 1901, p. 901). Esta elección del tiempo de caza era parte de un calendario cultural, que coincidía con las pariciones de fines de primavera y verano y el espacio entre las siembras y las cosechas agrícolas en sus lugares de procedencia. Se sabe que los loberos procedían preferentemente del sur de Chiloé, de la costa de Payos y, especialmente de la isla Cailin (García, 1889) y Chaulinec (Moraleda, 1888). Otros, viajaban desde la islas Laitec y Chaiguao, y de Quellón y Compu (Lincoman, 1990, p. 82).

Respecto de la actividad ganadera no existen muchos antecedentes de las labores y tareas que se desarrollaban en torno a la crianza de ovinos y caprinos en las islas de Guaitecas y Chonos. Se sabe que se les beneficiaba para obtener sebo $y$ carne ahumada. Los animales eran dejados en islas relativamente pequeñas pero dotadas de buen forraje (García, 1889; Simpson, 1872, 1874). En cuanto a las fechas de visita y revisión del ganado, estas deben haber estado asociadas a las pariciones de primavera y a los periodos de beneficios de animales en marzo, como escribe Fitz Roy a través de este pasaje (canal Ninualac - Moraleda) solían ir dos veces al año para inspeccionar las pequeñas manadas de cabras o rebaños de ovejas que tenían entonces en aquellas islas exteriores (Huamblin e Ipun); asi como en otras, de las cuales creo que Lemu, una isla boscosa situada en el lado norte de la rada Vallenar, era una (Fitz Roy, 2013, p. 321). Sobre la procedencia de los ganaderos chilotes, aparece nuevamente la isla Cailin, la isla Chaulinec y la costa de payos (García, 1889; Moraleda, 1888; Simpson, 1874).

En otro ámbito, el oficio de la pesca -uno de los más antiguos-, se practicaba por los chilotes construyendo corrales, o pescando con anzuelos y redes. La principal actividad era la pesca con corrales, también denominados Treputo y Chepulo (Cárdenas \& Trujillo, 1978, p. 24), que aprovechaba las subidas y bajadas de mareas donde quedaban los peces cautivos y se podían recolectar casi en seco. El corral se construía con piedras, estacas y ramas. Con esta técnica se pescaban robalos y su carne era ahumada y llevada casi seca a las islas de Chiloé, donde eran cotizadas en periodos religiosos, como la Semana Santa (Simpson, 1872). Las especies de mayor profundidad como el congrio y el bacalao deben haberse pescado con lienzas y recibido el mismo tratamiento de ahumado y secado que los demás pescados. La extracción de mariscos, por su parte, era complementaria a la pesca y otros oficios. Se ejercía como una actividad de cuenta propia, que funcionó durante todo el siglo XIX y tiene una de las datas de los oficios prehispánicos en los conchales. Los pescadores y mariscadores eran expertos conocedores de las variaciones de la marea, pues en gran parte de ello dependía su trabajo. En los canales del norte y sur de estos archipiélagos las variaciones de mareas en verano exeden de dos metros; pero según supe después, esto es mui conocido de los mariscadores $i$ yo mismo lo volvi a observar más tarde en Tangbac (Simpson, 1872, p. 409).

$\mathrm{Si}$ bien se presupone que los pescadores 
y mariscadores provenían de diversas lugares del sur de Chiloé, también existían pescadores con residencia permanente en islas cercanas a las Guaitecas, como el caso de Pedro Lincomán Durante nuestra estadía, nos visitaba con frecuencia, trayéndonos pescado i marisco de mejor clase que los podíamos recoger nosotros, cuyas viandas cambiaba por galletas $i$ otros comestibles de a bordo (Simpson, 1874, p. 509). De allí, que la pesca sería una actividad permanente y cotidiana para los habitantes de la Guaitecas y Chonos, pero temporal para los que procedían de Chiloé, periodo que debió coincidir con otras actividades de caza y trabajo del ciprés ${ }^{8}$ (Fig. 2).

El oficio del hachero, cortadores de árboles, tenía larga historia en Chiloé, muy probablemente desde periodos prehispánicos, aunque en el periodo colonial fue desarrollado en torno a la explotación del alerce (Fitzroya cupresiode) que se extraía del Seno de Reloncavi, las faldas del volcán Calbuco y de los bosques de la cordillera del estero Leteo y Comau (Molina et al. 2006). El oficio hachero se ejerció en los archipiélagos de las Guaitecas y Chonos a mediados del siglo XIX con motivo de la explotación del ciprés (Morales, 2014). La forma de explotación del ciprés consistía en el uso del fuego para abrirse paso en el bosque, i despejar los cipresales de las quilas... Los árboles más gruesos aunque chamuscados, permanecen parados, i de éstos se elijen los a propósito para durmientes, despreciando los que por sus escazas dimensiones $u$ otras circunstancias, no llenan los requisitos (Simpson, 1871, p. 195). Estas formas de explotación del ciprés se considera un desastre ecológico (Torrejón et al. 2013) ya que el uso del fuego implicaba la quema de islas enteras. Nosotros en las diferentes expediciones, observamos más de doscientas millas de bosques destruidos, i esto es una pequeña parte del todo (Simpson, 1871, p. 195). Para estas quemazones de cipresales se esperaban los días con buen tiempo: enteramente despejados i había reinado gran calor, los bosques estaban casi enteramente secos; i estas son las ocasiones, que no todos los años tiene lugar, de que se aprovechan los hacheros (Simpson, 1874, p. 517) y se advierte de

8 Como es sabido, en la actualidad la pesca artesanal y la extracción de mariscos sigue siendo una actividad importante en la costa de Aysén y mantiene la lógica la creencia que el incendio llama lluvia, sobre todo cuando se secan los arroyos de agua dulce en las islas, únicas fuentes de agua dulce, puesto que En las islas, la capa de tierra vejetal que cubre la roca primaria es sumamente delgada..; suerte que luego se seca i desaparecen las vertientes... I ésta es otra de las razones que tienen para incendiar el bosque, pues creen que con este remedio se llama la lluvia, o como ellos expresan, lo hacen para que malée (Simpson, 1874, p. 517).

El sistema de trabajo de los hacheros del ciprés era considerado feudal, por obligación y en retribución al pago de bienes obtenidos en Chiloé. El hachero trabaja por obligación, es decir, en pago de ciertas deuda contraída el invierno anterior en la tienda de raya, i además tiene que cubrir su pasaje de ida y vuelta, como también los viveres que consume en la faena, teniendo los trozos de madera que cortan un avaluó fijo, según las diferentes dimensiones estipuladas. De esto resulta generalmente que las partidas abandonan todo trabajo en cuanto calculan haber cumplido,... lo que además significa, que ya tenían otra vez abierta la tienda de raya para sus pedidos del invierno próximo.(Simpson, 1872, pp. 421-422). Cada empresario se encuentra establecido en algún pueblo de Chiloé i en este punto, de dónde saca sus hacheros, tiene su 'tienda de raya'. Durante el invierno, adelanta a éstos; a un precio exorbitante, los jéneros $i$ golosinas de que han menester, adeudándolos dentro de ciertos límites (Simpson, 1871, p. 195) Contraída la deuda en el invierno y llegada la primavera, los obligan a salir a trabajar en el archipiélago en pago de la deuda... Fuera de esto, les facilitan más jéneros, viveres $i$ aun licores durante las faenas $i$ así los esclavizan, pues casi todo chilote es propietario i no puede huir demanda judicial (Simpson, 1871, pp. 195196). Agregando el mismo autor la mayoría de los hacheros sale de Chonchi, Payos i Castro, distinguiéndose los primeros por un gorro tejido de lana i ajustado a la cabeza, del cual se escapan sus largas melenas (Simpson, 1872, p. 422). Así, desde Castro hasta la isla Cailin, parte sur de la Isla Grande de Chiloé, parte de la población se

de la ocupación a que hacemos mención: movilidad y estacionalidad discontinua. 
Fig. 2. Temporalidad y permanencia de la ocupación indígena-chilota, siglo XIX.

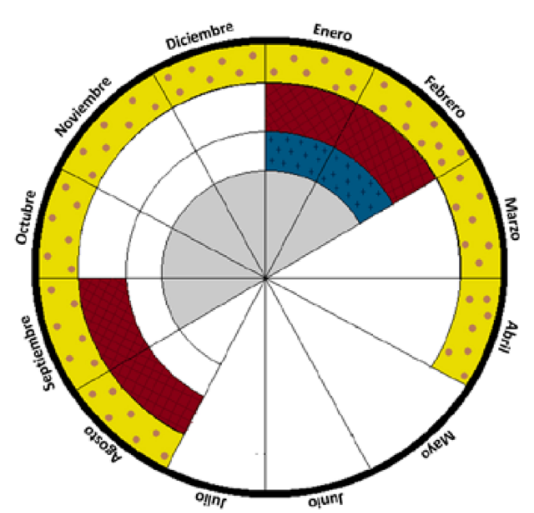

enrolaba como hachero en el trabajo de la corta del ciprés.

Además existían los patrones de balandras que reparten los hacheros, que traen generalmente en duos o trios, en los cipresales, dejándoles viveres para tres o cuatro meses... Al debido tiempo hacen la ronda de los puestos recojiendo las maderas, i completo el cargamento de la balandra, se dirigen con él a Melinka o a Chiloé (Simpson, 1872, p. 421). Los lugares donde eran llevados los hacheros eran diversos. Se advierte su presencia en Queulat y en diversas islas. También al sur del Canal de Pelluche (Aysén) por todas partes se notarán vestigios de chilotes y en el canal Agüea o Darwin, A uno $y$ otro lado se verá el bosque quemado i con toda probabilidad se avistará humo o alguna embarcación (Simpson, 1871. p. 194). En esto lugares de trabajo y asentamiento, los hacheros tenían por únicos alimentos papas, harina prieta $i$ mariscos, i vivian en una mala choza construida por ellos mismos (Simpson, 1872, p. 412). Otro navegante agrega que Su comida consiste principalmente en harina tostada, papas, mariscos i pescado, fuera de cuyos artículos casi no conocen otra clase de alimentos (Pendavis, 1872, p. 453). En el estuario Aau, unos hacheros habian estado aqui ya tres meses i acopiado una buena cantidad de madera para pagar su deuda

9 Enrique Simpson advierte de los peligros e incertidumbre del regreso a Chiloé que padecían los hacheros: A veces, como es natural, se atrasan las balandras i los hacheros permanecen algún tiempo sin más recursos que el marisco i el sargazo. En el caso de pérdida de la balandra, lo que suele acontecer, como solo el
Trabajo del Ciprés / Temporada de Hacheros

Loberos chilotes-Indígenas

Trabajo en la Pesca y Marisco

Temporada ganadera

Ocupación permanente en Guaitecas en

labores de pesca, caza, recolección y maderas. del invierno pasado (Simpson, 1872, p. 412). El trabajo en los cipresales comenzaba en octubre y se prolongaba hasta el mes de febrero o marzo, aproximadamente cuatro a cinco o seis meses. Terminada la temporada o cumplido el trabajo, los hacheros eran recogidos por el mismo patrón de balandra para regresarlos a Chiloé. Esto ocurría En la última ronda (de retiro de maderas), es decir, a fines de la estación o cuando los hacheros hayan cumplido obligación los recojen i los llevan a sus pueblos en Chiloé (Simpson, 1872, p. 421) ${ }^{9}$. En el Canal de Moraleda, Simpson anota a fines del mes de febrero En estos días pasaron para el norte, desde los estuarios i canales del sur, muchas balandras cargadas de hacheros de regreso a Chiloé, donde se dirijen en esta estación para asistir a las cosechas (Simpson, 1872, p. 420).

Otros autores coinciden en la temporalidad de la ocupación, pero admiten que algunos hacheros desarrollan un poblamiento más permanente en las islas del archipiélago de los Chonos: sus habitantes son moradores de temporada que, desde Chiloé ó Melinka, se dirigen a él para la explotación de madera de ciprés y otros árboles, abandonándolo en seguida cuando entre el invierno. Pocas veces suelen invernar en los Chonos algunos grupos reducidos de labradores (Vidal, 1905, p. 8). El poblamiento de los hacheros proveniente del sur patrón conoce el paradero de su jente, puede esta correr peligro de muerte por hambre, pues no en todas partes existe marisco, i en este caso su único medio de salvación es la canoa o bongo" (Simpson, 1871, p. 421). 
de Chiloé era comúnmente temporal, pero ya se acepta que algunos de ellos permanecen todos el año en el archipiélago de los Chonos.

De lo analizado en este acápite, se puede concluir tres elementos para comprender la ocupación chilota-indígena de los archipiélagos de las Guaitecas y de los Chonos. El primero, la ocupación está relacionada con actividades económicas que realizan por cuenta propia $y$ en oficios tradicionales como la caza, la pesca y recolección marina y las actividades agropecuarias, todas las que presentan evidencias de su ejercicio pretérito y en prácticas contemporáneas. Solo a mediados del siglo XIX, se suma la actividad de explotación del ciprés donde los chilotes despliegan su oficio de hacheros preferentemente en el archipiélago de Chonos, donde existe mayor abundancia de estos bosques. El segundo aspecto corresponde al tiempo de permanencia, siendo evidente que el poblamiento chilote es principalmente temporal y móvil, pero también es posible advertir la existencia de un poblamiento permanente más reducido y acotado, en algunas islas cercana a Melinka o en la zona de los Chonos. La temporalidad del poblamiento entre los hacheros alcanza de cuatro a cinco meses, principalmente de primavera a verano y, en el caso de los loberos, ocupan esta zona en los meses de enero y febrero. En otras actividades, como la agricultura, la pesca y la ganadería no ha sido posible identificar los meses de estadía ${ }^{10}$. El tercer aspecto, se relaciona con la procedencia de la población en el siglo XIX. Esta viene mayoritariamente de Chiloé, preferentemente de la costa de Payos, de las islas Cailin y Chaulinec y, en el caso de hacheros, se incorpora población de Castro a Chonchi.

Por tanto, las movilidades, viajes $y$ economías, todas resorte de una geografía social poco visibilizada hasta el día de hoy, develan la existencia de un poblamiento disperso, de baja densidad, pero continúo a través del tiempo, siendo estas ocupaciones parte de una articulación económica y social que vincula a los archipiélagos de Chiloé, de las Guaitecas y de los Chonos. La pregunta que nos queda pendiente es: ¿Quiénes son étnicamente los hacheros, loberos,

10 No se debe perder de vista, que la densidad del bosque fue un importante factor que impactó en la penetración hacia el interior continental. agricultores, prácticos, ganaderos que ocupan de modo temporal o permanente, las diversas islas de los archipiélagos de las Guaitecas y de los Chonos?

\section{IDENTIDAD INDIGENA DE LOS POBLADORES DE LOS ARCHIPÍELAGOS}

La denominación "chilote", usada para hacheros, pescadores, loberos, ganaderos y agricultores que ocupan los archipiélagos de las Guaitecas y de los Chonos en el siglo XIX, corresponde a una identidad local, un gentilicio que aúna la diversidad social y étnica del archipiélago de Chiloé. Lo "chilote" no es un concepto social y étnicamente uniforme, más bien es una multiétnicidad (Cárdenas \& Trujillo, 1978), advertida en las primeras décadas del siglo XIX por los viajeros extranjeros Hay cuatro clases distintas de habitantes de Chiloé y las Islas Adyacentes; el aborigen huyhuen-che o chonos; el huilli-che procede del sur de Chile; los extranjeros, que no han nacido en Chiloé no son descendientes de chilotes; y los criollos (Fitz Roy, 2013, p. 330). Se distinguen cuatro identidades, dos de ellas indígenas: la huyhuenche o chonos y la huilliche. Esta diferenciación nos desafía a descubrir "lo indígena" en el periodo republicano, cuestión que se encuentra mayormente invisibilizada a diferencia del periodo colonial donde los indígenas están individualizados debido a una estructura social de castas (García, 1889; Moraleda, 1888). A los indígenas que viven en la parte sur de la isla de Chiloé se les asocia, a fines del siglo XVIII y primeras décadas del XX, como descendientes de los Chonos, siendo la mayoría navegantes que viajan a los archipiélagos de las Guaitecas y de los Chonos. Se les nombra en los relatos hispano-coloniales y, hasta la década de 1830, con diversos etnónimos: chonos, caucahues (García, 1889), guaihuenes (Moraleda, 1888; Fitz Roy, 2013) o payos (Moraleda, 1888; Latcham, 1933; Cárdenas et al. 1991; Urbina, 2007) ${ }^{11}$. De modo que entrado el siglo decimonónico, los Chonos se niegan a desvanecerse como categoría étnica Los Chonos están ahora casi desaparecidos... solo se encuentran en la parte sur (de Chiloé), dice Fitz

11 A los indígenas de la Isla Cailin, los antiguos chonos, el padre García en 1766 los denomina "Caucahues", luego a los mismos de Cailin se les denomina Huyhue-che por Fitz Roy. 
Roy (2013, p. 330). Se refiere a su presencia en la Costa de Payos, de Queilen a Quellón, e islas inmediatas, entre ellas Cailin y Chaulinec. Hemos visto que a esta zona geográfica pertenece la mayoría de los loberos, pescadores, ganaderos y hacheros que hacen los periplos temporales o que permanecen todo el año en los archipiélagos de Guaitecas y de los Chonos.

$\mathrm{Al}$ analizar los nombres que llevan los ocupantes de las islas Guaitecas y de los Chonos, se puede constatar que la mayoría de ellos poseen apellidos indígenas, de origen huilliche y otros posiblemente chonos. Esto permite aseverar que el poblamiento de los archipiélagos durante el siglo XIX, aunque multiétnico, será preferentemente indígena. Para sostener esta afirmación se desatacan los datos que nos hablan de la identidad étnica y territorial, y de las articulaciones de estos espacios insulares que hemos recopilados de diversas fuentes.

Comenzaremos por los prácticos, geógrafos indigenas, que conocen los canales, los lugares y los paisajes de los territorios insulares. Los prácticos fueron indispensables para guiar a los navegantes y exploradores de los siglos XVIII y XIX por los canales e islas de las Guaitecas y de los Chonos. Ellos llevaban el derrotero y nombraban los lugares, sabían de los puertos, y de las zonas de caza y recolección. También, guardaban la memoria histórica de estos espacios insulares que visitaban al parecer, cada año. Por ejemplo, en el viaje del Padre García de 1766, son los indios caucahues, los que ofician de prácticos. Salen el 23 de octubre de la Isla Cailin, cinco españoles, treinta i cuatro indios caucahues $i$ yo, el padre José Garcia (García, 1889, p. 4). Los caucahues lo conducen por los canales hasta más allá del Itsmo de Ofquí, realizando la misma ruta de navegación que en años anteriores consumaron para ir a convencer a los Taijatafes y Calenes, además de otros familiares, para que se radicaran en las misiones de Chiloé. El etnonimo caucahues, correspondería genéricamente a Chonos, aunque algunos afirman tendrían distinta lengua, pero igual cultura material y modos de vidas (Urbina, 2007). Los caucahues serían un clan o comunidad, que se encuentra unido por lazos de parentesco y que ocupó zonas específicas en los archipiélagos del sur, pero formando parte del pueblo chono.
Moraleda, rescata el nombre de un caucahue de la expedición del Padre García. Se trata de Silvestre Mariantihue, que hoy existe (en 1793) (Moraleda 1888, p. 342). Es preciso observar que los antiguos caucahues llevan apellidos huilliche, muy probablemente rebautizados en las misiones, con un nombre del calendario cristiano -Silvestrey uno aparentemente huilliche -Mariantihue-. Lo sobresaliente del Diario de Viaje de José García (1889) es que da cuenta como los indígenas de la misión de Cailin no han dejado de navegar y ocupar económicamente los archipiélagos de Guaitecas y de los Chonos a pesar de estar radicados en Chiloé. Esta movilidad les permite un conocimiento del espacio insular que van develando al nombrar topónimos, identificando lugares de caza de lobos y mostrando las islas donde tienen ganado caprino y ovino, mientras conducen la navegación a los puertos de recalada. A fines del siglo XVIII, José de Moraleda comprueba que los Guaiguenes o Chonos, o indios del sur, mantienen el poblamiento de la Isla Cailin hasta 1781, cuando la abandonan persuadidos por la autoridad española para que se radiquen en la Isla Chaulinec. Pero las desavenencias entre indígenas de Cailin y de Chaulinec, que podrían ser de periodos previos a la radicación en Chiloé, obliga en 1790, a autorizar el regreso a los de Cailin a sus tierras e inmediatamente se trasladaron con su gobernadorcillo Sebastían Chillau a su antigua residencia de Cailin las 22 personas de uno i otro sexo que la habitan hace ya dos años (Moraleda, 1888, p. 307).

Los prácticos que acompañan a José de Moraleda en 1793 en su viaje a los archipiélagos de las Guaitecas y de los Chonos, pertenecen a chonos de la Isla Chaulinec. Se trata de Pedro Yaña, Antonio Hueñupal, Manuel Tuba i Luis Hueñupal (Moraleda, 1888, p. 371). Asegura que Antonio Hueñupal, (es) el mejor práctico del archipiélago, i especialmente de los canales que salen al oeste, por cuyas bocas ha pasado muchas veces dirijiéndose a las islas en que como ya he dicho, tiene su ganado (Moraleda, 1888, p. 331). Reconoce que el archipiélago de las Guaitecas y de los Chonos, no ha sido abandonado por los indígenas radicados en Chiloé, cuya identidad étnica puede atisbarse en los apellidos huilliches -Hueñupal-, aunque Yaña y Tuba, podrían 
corresponde a la lengua chona. Moraleda agrega que el apellido de uno de los prácticos es Hueñupal o Alloupa, este ultimo nombre probablemente chono. Étnicamente, los prácticos de la Isla Chaulinec, serían parte de los chonos que llegaron primero a la Isla Guar, en 1710, luego la mayoría abandonaron esta isla para radicarse en 1730 en Quiapu, en la isla de Quinchao, para desde aquí migrar en distintas direcciones, y establecerse en la isla Apiao y Chaulinec, que fueron destinadas para estos efectos de radicación por las autoridades españolas (Urbina, 2007, p. 340) ${ }^{12}$.

En las postrimerías del siglo XVIII, los antiguos chonos de Chaulinec continúan sus ocupaciones económicas al sur del golfo Corcovado El práctico Pedro Yaña, que me acompaña, ha tenido potrero de ganados en dicho Aisen (Moraleda, 1888, p. 317)... su potrero lo tuvo en la Isla Setucápel,... que su ganado se lo robaron hace trece años unos indios jentiles, que habiendo sido traídos de la tierra firme del sur del istmo de Ofqui el año 1779, en número de 35 almas de ambas sexos, los mas niños, por los misioneros frai Francisco Menendez i frai Ignacio Vargas i dándoles domicilio en la isla de Lemui, de Chiloé, mal hallados con nuestra religión se huyeron todos en una piragua antes del año de residencia en dicho lugar, i dirijiéndose a su tierra pasaron por el citado i se llevaron todo el ganado, en número de 50 cabezas de carneros $i$ ovejas, que eran los que el Yaña tenía (Moraleda, 1888, p. 332). Además, los prácticos Antonio y Luis Hueñupal tienen ganado en varias islas; estoi instruido que solo se da en alguna abundancia (el pasto y el ganado) en las islas Iquilao, Quimanec, Ayoupa, Tenquehuen, Menchuan i Meñan ( se ha dicho que esta es Inchemó) son las únicas de todo el archipiélago que con este motivo tiene ganado lanar i cabrío, perteneciente a Antonio i Luis Hueñupal, hermanos, habitantes de la de Chaulinec, en Chiloé, los cuales vienen casi todos los años a hacer charqui o tasajo de él i a aprovecharse del sebo (Moraleda, 1888, p. 329). Además, en las islas Guamblin e Ipun su padre Domingo Hueñupal estuvo en ambas i que él (Antonio) las ha visto muchas veces (Moraleda, 1888, p. 331) (El destacado es nuestro). Esto

12 Incluso la tenencia de ganado y el cultivo de papas y maíz en las Guaitecas se remonta al siglo XVII. En esos años, demuestra una tradición de ocupación ganadera transgeneracional en diversas islas del archipiélago de los Chonos en el siglo XVIII, que se proyecta al siglo XIX.

La movilidad, el uso y la ocupación productiva de los espacios insulares la sur de Chiloé por los descendientes de los Chonos (caucahues) de las islas de Cailin y de Chaulinec, donde a 1795, se identificaban a 25 familias que forman parte de la etnia de la Chonos (Mena, 1985), demuestra que, con posterioridad a su radicación en Chiloé, siguieron ocupando estos espacios insulares y desarrollando actividades como la caza de lobos marinos y ballenas, que les permitían el comercio y el intercambio. Estos indígenas en Chiloé, no estuvieron ajenos a los procesos de aculturación que significó la perdida de la lengua y del asentamiento semi nómada que señala Urbina (2007), aunque no implicaron la pérdida de sus actividades tradicionales y de su condición indígena, sin abandonar ellos y sus descendientes, su antigua territorialidad en las islas Guaitecas y en el archipiélago de los Chonos.

Con los inicios de la república en Chiloé (1825) declina la información sobre los indígenas e identidades étnicas locales, no porque hayan desparecido, sino porque la política de invisibilización y homogenización nacional, genera un ocultamiento del indígena. Sin embargo, es posible encontrar información para seguir la huella de la ocupación indígena en los archipiélagos de Guaitecas y de los Chonos, aunque para la primera mitad del siglo XIX ella es más escasa, pues los escritos se refieren genéricamente, en la mayoría de las veces, a "los chilotes". Por ejemplo, Fitz Roy en 1832, señala que el piloto del Adventure, Sr. Low, que deja su nombre en el primer puerto de las Guaitecas, se dedicará a explorar el archipiélago de los chonos llevando un bote ballenero y una tripulación de nativos (chilotes) (Fitz Roy, 2013, p. 319), pero no agrega nuevos datos, solo dice que volvieron a la isla Cailin. Luego nombra a las piraguas con chilotes que han llegado a Puerto Low, en viaje en busca de lobos y nutrias, sin señalar su procedencia e identidad indígena. Finalmente, la indiferenciación étnica, se refleja cuando escribe

el cacique de los chono Pedro Delco cultivaba en las islas Guaitecas. (Torrejón et al. 2013, p. 38) 
Tabla 3. Indígenas que ocupan los archipiélagos de Guaitecas y de los Chonos (1766 a 1901).

\begin{tabular}{|c|c|c|c|}
\hline Nombres Indígenas & Actividad que realiza & Año & Fuente \\
\hline Silvestre Mariantihue & Parte expedición de José García & 1766 & José García, 1889 \\
\hline Sebastían Chillau & Cacique de isla Cailin & 1793 & Moraleda, 1888 \\
\hline $\begin{array}{l}\text { Pedro Yaña, Antonio Alloupa o Huenupall y } \\
\text { Luis Hueñupal }\end{array}$ & $\begin{array}{l}\text { Prácticos y potreros en Isla Setucápel y en } \\
\text { isla Inchemó }\end{array}$ & 1793 & Moraleda, 1888 \\
\hline Manuel Tuba & Práctico & 1793 & Moraleda, 1888 \\
\hline Domingo Hueñupal & Tuvo animales en isla Guamblin e Ipún & 1793 & Moraleda, 1888 \\
\hline Juan Yates & Práctico de Fitz Roy y de Enrique Simpson & $\begin{array}{l}1834 \\
1872\end{array}$ & Simpson, 1972 \\
\hline Pedro Lincomán & Habitante ancestral de isla Puquitin & 1890 & Vidal, 1905 \\
\hline $\begin{array}{l}\text { Pedro Ñancupel, Ramón Colipichun, Cecilio } \\
\text { Teca }\end{array}$ & $\begin{array}{l}\text { Testigos que pueden dar cuenta de pes- } \\
\text { cadores desaparecidos en Guaitecas y } \\
\text { Chonos }\end{array}$ & 1878 & $\begin{array}{l}\text { Diario El Chilote, } \\
1878\end{array}$ \\
\hline
\end{tabular}

Domingo Nagüelguen Chiguai, Juan Andrés Nahulehuen Millacari, Juan Antonio Nahuelhuen Siuco, José Manuel Nahuelhuen Siuco, Juan Andrés Piuco Linnan, Antonio Piuco Nitor, Juan Ignacio Lepio Tavie, Pascual Lepio, Juan Lepio i Lepio, Cecilio Teca Tavie, Santiago Cuyul Melipillan, Domingo Yana Carimonei, Bruno Güemul Melipillan, Agustín Colin Cárdenas, Bernardino Levin Huala, Antonio Levin Guala, Pridencio Llancalahuen Quinan, José Perez Soto y Marciano Rain Chiguai

Nombres aparecidos en caso judicial de piratería en las Guaitecas, todos son loberos, labradores y pescadores. Domingo Nagüelguen vivía y tenía casa en canal 1878 Gaceta de los Puquitin y el resto en la costa de los payos Tribunales, 1879
Francisco Nagüelquin, Fermín Melipillan e Ignacio Taigue

Loberos y pescadores de Chonchi que van a la pesca en isla Tangbac, asaltados en puerto Low

Pedro María y Anastasio Nancupel, Belisario Catepillan

Manquemilla y sus compañeros

Pedro Manquemilla
Pescadores y loberos acusados de piratería en Puquitin

Lobero asaltado en Guaitecas

Pescador de Terao, sale de Puquitin en chulapón cargado de pescado. Perdido por mal tiempo
1878 Gaceta de los

Tribunales, 1879

1886 El Católico, 1888

1886 El Católico, 1888

La Cruz del Sur, 19011901

1901 La Cruz del Sur, Loberos, payanos de Cailin 1901

que en la isla Huafo vio muchas ovejas que pertenecen a chilotes, que viven en Caylin, redacción que podría haber sido "ovejas que pertenecen a los caucahues de Cailin". Fitz Roy, se limita a dar por fenecida esta asociación, al agregar Antes había indios en Huafo, llamados Huyhuen-che (Fitz Roy, 2013, p. 329).

La mayor parte del siglo XIX tendrá este enfoque supra étnico, aunque, como hemos visto, es factible escudriñar en los informes de las expediciones una activa presencia indígena
Chonos (Tabla 3). Enrique Simpson, en sus viajes de 1871 a 1874, contrata en Ancud a don Juan Yates, el más antiguo e idóneo: ha frecuentado el archipiélago durante 40 años, i además acompaño al almirante Fitz-Roy (Simpson, 1871, p. 161). Agrega es el sirviente más antiguo en estas rejiones (Simpson, 1871, p. 179). Juan Yates es un indígena lobero, posiblemente de ancestros chonos, que desde 1830 ha recorrido persistentemente las Guaitecas y el archipiélago de 
los Chonos, de la que ha adquirido su experiencia geográfica, puesto que julio de 1843 es contactado en la isla Tangbac. El viejo lobero don Juan Yate que se hallaba en ese punto (Puerto Americano) ofreció sus servicios indicando la comarca donde se hallaba el mejor ciprés (Guillermos, 1901, p. 20). El conocimiento indígena servirá a Simpson en su expedición para recabar antecedentes de la historia local y ambiental de las islas. Juan Yates, le informa de la extinción de los lobos elefantes que dan nombre a la punta homónima, en el camino a San Rafael. Le señala que el mismo abatió a varios Tan grande eran estos animales, que según el práctico, quien mato a varios, uno solo rindió ocho barriles de aceite, o sean, 400 litros (Simpson, 1871, p. 177). También, Yates relata que la vega del estuario Queulat, antes contenía... muchos cipreses, los que fueron esplotados en parte, pero el resto destruido, por la perniciosa costumbre de incendiar (Simpson, 1874, p. 516). Por ello, los prácticos de los canales serán indígenas que conocen, frecuentan y ocupan los archipiélagos al sur del Golfo Corcovado, desplegando sus oficios de loberos, ganaderos, pescadores y hacheros, quienes además, conservan la memoria de estos lugares, paisajes y territorios.

La expedición de Enrique Simpson duró cuatro largas temporadas y fue realizada coincidiendo con el periodo de mayor explotación de los bosques de ciprés, que atraían cada temporada a numerosos hacheros de Chiloé. Durante las largas recaladas de la nave Chacabuco, en puertos abrigados, como el de Laguna, cerca de la boca del fiordo de Aysén, el médico cirujano del barco, Guillermo Pendavis, atendió a numerosos hacheros. Allí hizo convicción de su identidad indígena y la atribuyó a descendientes de los chonos: los cortadores de madera..., vienen de las parte sur de esta isla (Chiloé). Se les supone jeneralmente ser descendientes de los chonos (Pendavis, 1872 , p. 453). Además, de los rasgos culturales, el cirujano en sus atenciones médicas, tomaba notas de la descripción anatómica que resaltaba como rasgos indígenas.

Por los mismos años de la década de 1870 se advertía que en las Guaitecas queda aun una familia paya, ultima reliquia de sus antiguos pobladores: vive de la pesca, de la corta de maderas de construcción, y poco de la agricultura.
Es semi-civilizada y se encuentra en frecuente trato con los labradores chilotes que explotan las islas (Vidal, 1905, p. 4). Cuando Vidal Gormaz se refiere a "familia paya" está diciendo familia de chonos. En efecto, por payos se conoce a los Chonos, dice Latcham (1933) y otro autor agrega que los payos son los chono que se establecieron en este archipiélago (Chiloé), es decir, que fueron delimitando un territorio adyacente a la isla Grande de Chiloé, especialmente en su área sur-oriental, manteniendo una vinculación permanente con los veliche, de los cuales fueron asimilando tipos de vida (Cárdenas et al. 1991, p. 96). En efecto, el nombre payos se conocía desde fines del siglo XVIII en Chiloé, nombrándose toda la parte sur de la isla grande como Costa de los Payos (Molina \& Correa, 1996). En efecto, La comarca llamada Payos es toda la comprendida al sur de Chonchi y hasta el estremo austral de la isla grande, mui especialmente la costa oriental, que es la parte poblada (Moraleda, 1888, p. 66, Nota 21). Esto incluye parte de la costa de Chonchî a Queilen y toda la costa de Compu, Huaipulli, Huequetrumao, Chaiguao, Quellón, Coldita y Yaldad, donde en el siglo XX sus habitantes seguirán siendo en su mayoría loberos, hacheros y mariscadores y a partir de la década de 1930 van a constituir comunidades huilliches (Molina, 1987).

La última familia paya en las Guaitecas a que refiere Vidal Gormaz, sin duda se trata de la de Pedro Lincomán que posee un poblamiento ancestral, a la que Enrique Simpson otorga el poder de alegar o atribuírsele la descendencia de los chono Hoy día no existe más que una sola familia nombrada Lincomán, que habita el canal Puquintín, que separa la isla Ascensión de la gran Guaiteca, que pueda pretender a la representación de la raza chona original. Esta familia, según dicho propio i testimonio del práctico Yates, quien la conoce desde 40 años atrás (1830), ha vivido siempre en el mismo punto donde la precedieron sus padres y abuelos. Pedro, el jefe, de estatura baja, frente chata i cara ancha, es bautizado; pero conserva los instintos primitivos de su raza, ocupándose de la pesca (Simpson, 1874, p. 598). La presencia de la familia Lincomán en el canal Puquintin, destaca la existencia de un poblamiento permanente y ancestral en las Guaitecas, que no 
había sido visualizado ${ }^{13}$.

Las fuentes de prensa también brindan noticias que permiten aproximarse a las identidades indígenas y chilota, a través de los apellidos de los ocupantes permanentes o temporales de los archipiélagos de las Guaitecas y de los Chonos. Los reportes de la prensa describen para fines del siglo XIX la presencia multiétnica, de indígenas y chilotes criollos, donde prevalecen los primeros. Por ejemplo, en marzo de 1878 se informa sobre varios desparecidos en los canales De los individuos que se ocupan de la pesca de lobos en las Islas Guaitecas han desaparecido seis a quienes se les considera muertos....Las personas que pueden declarar y están a disposición de VS. Son: Pedro Nancupel, Facundo Mancilla, Ramón Colipichun, Juan Andrés Aguilar y Cecilio Teca (Diario El Chilote 04/03/1878), es decir, tres indígenas y dos chilotes que están en los archipiélagos australes. Otros casos que dan noticias de la ocupación indígena de las Guaitecas y de los Chonos, en la década de 1870 y 1880 corresponden a informaciones de asaltos a loberos que han sido estudiados por Osorio (1987, 1988) como casos de piratería en las Guaitecas. Uno de los principales involucrados es Domingo Naguelguen, que en 1878 habitaba cerca de la isla Guaiteca Pues hai en aquel lugar de Puquitina una casa habitada por Domingo Nagüelguen...en la que iban a pasar sus temporadas varios indios de los confines de Payos, Chonchi y Lemui (Diario El Chilote 27/06/1878) ${ }^{14}$. Se informa que este grupo de indígenas acometieron en Puerto Low contra el lobero; Francisco Naguelquin (que) salió de Chonchi con tres más con el objeto de hacerla pesca de lobos y róbalos en Puerto Americano (Isla Tangbac cerca de Aysen) (Diario El Chilote 04/08/1878). Los compañeros de Nagüelquin eran Fermin Melipillan, Ignacio Taigue $i$ un muchacho cuyo nombre se ignora (Gaceta de los Tribunales, 1879 , p. 134). Nagüelguen, además

13 Al terminar esta investigación, los autores se encontraron con dos trabajos de Osorio (2014) y Osorio et al. (2007) que apuntan en la misma línea, es decir, a visibilizar una geografía social para Aysén de carácter móvil y diversa que ha estado silenciada desde las clásicas lecturas centroperiferia.

14 La Gaceta de los Tribunales de 1879, en su página 133, señala el nombre de los 22 condenados y absueltos; casi todos indígenas: Domingo Nagüelguen Chiguai, Juan acometió contra otra embarcación, cometiendo crímenes que fueron castigados en junio de 1879 . Vemos en estas noticias que todos los nombrados son indígenas y de oficios pescadores y loberos.

La segunda noticia se produce en 1886, cuando Pedro María Nancupel, natural de Chonchi y sus hermanos Anastasio y sus dos hijos, más Belisario Catepillan, andaban en la pesca de róbalos y caza de lobos y, en Puquitin, cerca de las Guaitecas, se les imputó haber dado muerte a los loberos Manquemilla y sus compañeros para apropiarse de viveres y enseres (El Católico 07/06/1888), pues Manquemilla tría en su chalupa dos redes, pescado, cuero de gato i lobo, i que de todo se habian apoderado con su hermano Anastacio (Gaceta de los Tribunales, 1888, p. 295). A Pedro Nancupel, se le describía como un hombre de regular estatura, delgado, con musculatura, de piel oscura claro como la gente de mar, entre los que él se ha contado hasta la fecha (Diario La Probidad de Ancud, 1886). Nancupel pasó los primeros años de su vida al servicio de un feliz especulador de las maderas de las Guaitecas i Chiloé, acostumbrado temprano su temperamento aventurero i atrevido, a todas las luchas de una vida de mar (Diario El Archipiélago 11/11/1888). Las imputaciones fueron negadas desde un principio por Nancupel, pero no salvo del cadalso lo que ha provocado un debate académico posterior (González, 2011) y ha dado en los archipiélagos, paso a la leyenda de las cuevas de Ñancupel (Molina, 1990).

El tránsito de loberos y pescadores entre Chiloé, las Guaitecas y el archipiélago de los Chonos cada cierto tiempo hará noticia, reportando la tragedia de tempestades o de hechos trágicos, como él que se publica en prensa chilota en 1901 Pedro Manquemilla, de Terao, comunica que en junio del año anterior salieron de Puquitin tres chalupones cargados de pescado. En San Pedro (isla cercana a Cailin) les sorprendió una tempestad que llevó al Continente a dos de

Andrés Nahulehuen Millcari, Juan Antonio Nahuelhuen Siuco, José Manuel Nahuelhuen Siuco, Juan Andrés Piuco Linnan, Antonio Piuco Nitor, Juan Ignacio Lepio Tavie, Pascual Lepio, Juan Lepio i Lepio, Cecilio Teca Tavie, Santiago Cuyul Melipillan, Domingo Yana Carimonei, Bruno Güemul Melipillan, Agustín Colin Cárdenas, Bernardino Levin Huala, Antonio Levin Guala, Pridencio Llancalahuen Quinan, José Perez Soto y Marciano Rain Chiguai. 
ellos. Calmado el tiempo regresaron las dos chalupas a Terao lugar de su residencia. Como la tercera chalupa no hubiese llegado se despachó otra en su busca. En el paraje llamado "Casa de Quilla" encontraron a la chalupa perdida (...) dentro aparejos, remos, hachas, etc. (...). De las 200 cargas de pescado no se encontró ninguna; pero se supo después que otro chalupón que trabajaba por allí, regreso a su tierra en un corto tiempo y cargado de pescado.... Se habla también de unos individuos Colovoros, payanos, que son excelentes gateros y loberos y diestros cazadores, y que merodean todo el año por ese archipiélago. Agregan que después que se perdió la chalupa de Terao los Colovoros regresaron a Cailin con cargamentos de pescado (Diario La Cruz del Sur 16/03/1901).

La continuidad histórica de la ocupación indígena de los archipiélagos de las Guaitecas y de los Chonos en el siglo XX se puede apreciar en los escritos del Cacique de Compu, don José Santos Lincomán. El poeta y escritor relata que él fue lobero junto a otros hombres de la costa de Payos. Salían a la caza de lobos en la isla Guamblin y otras cercanas en los meses de enero y febrero, iban los loberos de Cailin, Laitec y Chaiguao, de Quellón y Compu (Lincomán, 1990, p. 82). En su memoria y escritos aparece la referencia a los chonos como figura literaria y muy probablemente como asociación étnica pretérita. En la introducción a su cuento "Como se dividió Chiloé", para dar profundidad ancestral al relato dice Contaba mi ñuque y contaban mis abuelos, mis abuelos contaban que mis abuelos y más abuelos. Contaban mis tátaras abuelos y mis tátaras abuelas, contaban mis chonos abuelos (Lincomán, 1990, p. 84).

\section{CONCLUSIONES}

Hemos apreciado que la construcción de los archipiélagos de las Guaitecas y de los Chonos como un espacio vacío fue más bien una creación extra local, una proyección socio-cultural de

15 Aunque no lo hemos citado porque su trabajo ha llegado tardíamente a nuestras manos, deseamos destacar el diálogo entre esta propuesta y la interesante investigación desarrollada por Gonzalo Saavedra. A modo de ejemplo: Saavedra \& Navarro (2016). El Sur-austral en movimiento: extranjeros o de navegantes que visitaron poco tiempo la intrincada geografía de canales e islas. Al contrario, se ha logrado establecer la existencia de una ocupación temporal a lo largo del siglo XIX, asociada a la explotación tradicional de recursos ambientales de la geografía insular, articulada desde la parte sur del archipiélago de Chiloé. El imaginario despoblado y solitario que se construyó para estos archipiélagos, es desmentido a través de la continuidad de un poblamiento indígena y multiétnico, vinculado principalmente a tareas y labores de loberos, pescadores, ganaderos y hacheros. En el caso del poblamiento permanente la literatura tradicional y algunos informes, la circunscriben a la fundación del puerto de Melinka a mediados del siglo XIX y al establecimiento conservero de la isla Tangbac en la década de 1870. Sin embargo, hemos podido apreciar que se agregan otros asentamientos indígenas permanentes o semipermanentes, que no estaban visibilizados en las islas Guaitecas.

Como sea, la ocupación de Melinka y las denominadas "concesiones ganaderas", otorgadas por la agencia central estatal a comienzos del siglo $\mathrm{XX}$, serían el inicio de una ocupación llamada "real" o "permanente", fijando en esa característica la condición de una geografía e historia que solo es visible en relación al marco textual dado por una homogenización territorial de escala nacional (Núñez, 2009). De alli que los relatos de una geografía social de la Patagonia costera hayan sido solo complementos menores -y no un elemento central- al momento de proyectar un imaginario geográfico para la zona. Aquella proyección, como indicásemos al inicio, es condescendiente con los silencios geográficos que se resaltan al momento de hablar de estas llamadas "tierras de entremedio", incluso en las primeras décadas del siglo $\mathrm{XX}^{15}$.

Sin embargo, hemos podido constatar que las ocupaciones de los archipiélagos son principalmente indígenas y presentan continuidad a través de prácticas productivas tradicionales que se han rastreado desde el siglo XVIII. Estas obedecen a un sistema de ocupación basado en la

Itinerarios chilotes en Patagonia insular occidental. En A. Kottow \& A. Traverso (Eds.), Diálogos culturales/ Imaginarios nacionales: Viajes, territorios e identidades (pp. 139-15). 7. Santiago: RIL. 
caza, la recolección y pesca marina, la ganadería y una escasa agricultura. Sólo a mediados del siglo XIX, se incorpora el hachero de modo intensivo, asociado a la explotación del ciprés, proceso económico que incrementa la ocupación económica de los archipiélagos, especialmente en la zona entre el estero Aysén y la península del Taitao, donde se encontraban las mayores reservas de ciprés. A su vez, hemos analizado que los oficios de lobero, pescadores, ganaderos, hacheros $y$ prácticos marinos, han estado mayoritariamente asociados a indígenas que han ocupado en el tiempo los archipiélagos de las Guaitecas y de los Chonos. Estos en su mayoría son descendientes de los antiguos Chonos, incluyendo a los llamados Caucahues, que se radicaron en el siglo XVIII en el archipiélago de Chiloé y que a inicios del siglo XIX se encontraban ocupando preferentemente la costa de payos, o costa de los Chonos y las islas Chaulinec y Cailin. Desde estos asentamientos continuaron articulando un espacio económico ancestral, que comprendió la parte sur de Chiloé y los archipiélagos de las Guaitecas y de los Chonos.

Por tanto, estos archipiélagos no fueron un espacio vacío. Por el contrario, es posible leer un texto geográfico cuya expresión es continuidad $y$ permanencia, es productividad y movilidad y, por lo mismo, puede ser interpretado como una periferia cuya centralidad se descifraba desde los agentes locales. Desde esta perspectiva, este trabajo plantea un problema actual: cómo los márgenes de la nación pueden comprenderse desde el espacio vivido, evitando o minimizando lecturas o interpretaciones marcadas por discursos del desarrollo muchas veces ajenas precisamente a esa experiencia del habitar.

\section{AGRADECIMIENTOS}

Los autores agradecen el apoyo de CONICYT-FONDECYT (proyecto N¹141169) y al Observatorio Hombre-Medio Bahía Exploradores, INEE, CNRS, desde donde se investigó y trabajó este texto.

\section{BIBLIOGRAFIA}

Albert, F. (1901). Los pinípedos en Chile. Anales de la Universidad de Chile. 108, 879-903.
Aliste, E., \& Núñez, A. (2015). Las fronteras del discurso geográfico: el tiempo y el espacio en las ciencias sociales. Revista Chungará, 47(2), 287-301.

Bandieri, A. (2011). Historia de la Patagonia. Buenos Aires: Sudamericana

Beranger, C. (1893). Relación Jeográfica de la Provincia de Chiloé. Santiago: Imprenta Cervantes.

Bosquejo Jeográfico de la Provincia de Chiloé, Imprenta del Mercurio, Valparaíso 1851.

Bourdieu, P. (1988). Cosas dichas. Buenos Aires: Gedisa.

Cárdenas, R., \& Trujillo, C. A. (1978). Apuntes para un diccionario de Chiloé. Castro, Chiloé: Ediciones Aumén.

Cárdenas, R., Montiel D., \& Grace, C. (1991). Los chonos y los veliche de Chiloé. Santiago: Olimpho.

Cavada, F. (1914). Chiloé y los chilotes. Estudios de folklore y Iingüística de la provincia de Chiloé (República de Chile) acompañados de un vocabulario de chilotismos y precedidos de una breve Reseña Histórica del Archipiélago. Santiago: Imprenta Universitaria.

Darwin, Ch. (1945). Viaje de un naturalista alrededor del mundo. Buenos Aires: Librería El Ateneo.

Emperaire, J. (2002) Los nómades del mar. Santiago, Chile: LOM.

Fitz Roy, R. (2013). Viajes del Adventure y el Beagle. Santiago: La Catarata.

Foucault, M. (1967) "Espacios otros". Conferencia pronunciada en el Círculo de Estudios Arquitectónicos, El 14 de marzo de 1967 publicada en Architecture, Mouvement, Continuité, n5, octubre de 1984.

Foucault, M. (1997). La arqueología del saber. México: Siglo Veintiuno Editores.

Flores, C., \& Lira, N. (2006). Aspectos comunes para sitios de cazadores recolectores costeros en los canales patagónicos septentrionales. Boletín de la Sociedad Chilena de Arqueología, 112, 103-139.

Gaceta de los Tribunales (1879). Sentencia Contra Domingo Nahuelhuen Chiguai y otros por piratería i homicidio. Santiago, 222, 133-135.

Gaceta de los Tribunales (1888). Corte de Apelaciones de Concepción. Sentencias Criminales Contra Pedro María Nancupel i otros, por homicidio. Santiago, 2112, 294-296.

García, J. (1889). Diario del viaje i navegación hechos por el Padre José García, de la Compañía de Jesús, desde su misión de Caylín, en Chiloé hacia el sur, en los años 1766 i 1767. Anuario Hidrográfico de Chile, 14, $3-42$

González, J. (2011) Aspectos generales de la representación 
de Pedro Ñancupel en la narrativa de ficción histórica contemporánea. III Seminario "Chiloé: Historia del Contacto". Santiago: DIBAM. Consultado desde http:// www.dibam.cl/Recursos/Contenidos\%5CDe\%20 Ancud\% 5 Carchivos\% 5 CASPECTOS\% 20 GENERALES\% 20 D E \% 20 L A \% 20 REPRESENTACI\%C3\%93N\%20DE\%20PEDRO\%20 \%C3\%91ANCUPEL.pdf

Guillermos, J. (1901). Diario de Viaje de la Goleta Ancud al mando del Capitán de Fragata don Juan Guillermos (1843), para tomar posesión del Estrecho de Magallanes. Santiago, Chile: Imprenta y litografía Barcelona.

Ibar Bruce, J. (1960). Ensayo sobre los indios chonos e interpretación de sus tiponimias. Anales de la Universidad de Chile, 117, 61-70.

Latcham, R. (1933). El elemento indigena de la región austral. Valdivia: Turismo Austral.

Lincomán, J. S. (1990). Poesía y Cuento. Chonchi, Chiloé: OPDECH.

Lindón, A., \& Hiernaux, D. (Eds.) (2012). Geografías de lo imaginario. México: UAM, Anthropos.

Lois, C. (2014). Mapas para la nación. Episodios en la Cartografía Argentina. Buenos Aires: Editorial Biblos.

Martinic, M. (2005). De la Trapananda al Áysen: Una mirada reflexiva sobre el acontecer de la Región de Aysén desde la prehistoria hasta nuestros días. Santiago: Pehuen Editores.

Mena. F. (1985). Presencia indígena en el litoral de Aysén. Trapananda. 5, 203-213.

Mignolo, W. (2011). Historias locales/diseños globales. Colonialidad, conocimientos sualternos y pensamiento fronterizo. Madrid: Akal.

Molina, R. (1987). El Pueblo Huilliche de Chiloé. Elementos para su historia. Chonchi, Chiloé: OPDECH.

Molina, R. (1990). Nancupel, pirata de las Guaitecas: "Sepultado sin entierro". El Canelo, Revista de Desarrollo Local, 4, 12, 11-13.

Molina, R., \& Correa, M. (1996). Territorios Huilliches de Chiloé. Santiago: Corporación Nacional de Desarrollo Indígena y Agencia Española de Cooperación Internacional.

Molina, R., Correa, M., Gainza, A., \& Smith-Ramírez C. (2006). Alerceros Huilliches de la Cordillera de la Costa de Osorno. Santiago: Andros.

Moraleda, J. (1888). Esploraciones Jeograficas e Hidrograficas de José de Moraleda i Montero. Santiago: Imprenta Nacional.

Morales, D. (2014). El negocio de la Madera: Comerciantes y
"Hacheros" de Chiloé, 1850-1875. Magallania, 42, 41-60.

Núñez, A. (2009). La Formación y consolidación de la representación moderna del territorio en Chile: 1700- 1900. Tesis para optar al grado de Doctor en Historia. Facultad de Historia, Geografía y Ciencia Política. Universidad Católica de Chile.

Nuñez, A. (2013). Definiendo una geografía para la nación: la re-significación territorial de Chile, siglos XVIII-XIX. En Q. Bonastra, G. Jori, (Eds.), Poder, territorialización y socialización en los orígenes del Estado-nación (pp. 167-197). Barcelona: Icaria.

Núñez, A., Sánchez, R., \& Arenas, F. (2013). Fronteras en movimiento e imaginarios geográficos. La cordillera de Los Andes como espacio cultural. Santiago: RILGeolibros.

Núñez A., Aliste, E., \& Bello, A. (2014a). El discurso del desarrollo en Patagonia-Aysén: la conservación y la protección de la naturaleza como dispositivos de una renovada colonización. Chile, siglos XX-XXI. Scripta Nova, XVIII (493), 1-13.

Núñez, A., Aliste, E., \& Bello, A. (2014b). Patagonia - Aysén en la construcción del imaginario geográfico de la nación. Itzapalapa Revista de Ciencias Sociales y Humanidades, 76, 165-188.

Olguín, C. (1981). Instituciones políticas y administrativas de Chiloé. Santiago: Editorial Jurídica de Chile.

Osorio, C. (1987). Piratas en las Guaitecas. Cultura de \& desde Chiloé, 7, 15-17.

Osorio, C. (1988). Un caso de piratería nativa en Chiloé. Revista Cultura De \& desde Chiloé . 8, 3-4

Osorio, M. (2014). Antiguas historias del valle Simpson. Aysén: Ediciones Nire Negro.

Osorio, M., Saavedra, G., \& Velásquez, H. (2007). Otras narrativas en Patagonia. Tres miradas antropológicas a la región de Aisén. Aysén: Ediciones Nire Negro.

Pendavis, G. (1872). Apéndice E. Materia médica e historia natural. Anales de la Universidad. 1, 451-457.

Peri, R. (1989). Reseña de la Colonización en Chile. Santiago: Andrés Bello.

Reyes, O., Méndez, C., San Román, M., Cárdenas, P., Velásquez, H., Trejo, V., \& Stern, C. (2007). Seno Gala 1: Nuevos resultados en la arqueología de los canales septentrionales ( $44^{\circ} \mathrm{S}$, Región de Aisén, Chile). Magallania, 35(2), 105-119.

Reyes, O., Méndez, C., Maldonado, A., Velásquez, H., Trejo, V., Cárdenas M., \& Abarzúa, A. M. (2009). Uso del espacio de cazadores recolectores y paleoambiente holoceno en el valle del río Cisnes, Región de Aisén, 
Chile. Magallania, 37(2), 91-107.

Reyes, O., San Román, M., \& Moraga. M. (2011). Archipiélago de los Chonos: nuevos registros arqueológicos $y$ bioantropológicos en los canales septentrionales. Isla Traiguén, Región de Aysén. Magallania, 39(2), 293301.

Saavedra, G., \& Navarro, M. (2016). El Sur-austral en movimiento: Itinerarios chilotes en Patagonia insular occidental. En A. Kottow \& A. Traverso (Eds.), Diálogos culturales/Imaginarios nacionales: Viajes, territorios e identidades (pp. 139-15). Santiago: RIL.

Said, E. (2010). Orientalismo. Barcelona: Debolsillo.

Simpson, E. (1871). Esploración de la costa occidental de Patagonia i de los archipiélagos de los Chonos i Guaitecas, practicada según orden del Supremo Gobierno, por don Enrique M. Simpson, a bordo de la corbeta "Chacabuco". Anales de la Universidad. Santiago, Chile, 169-197.

Simpson, E. (1872). Esploración de las costas occidentales de Patagonia i del archipiélago de los Chonos, practicado por orden del supremo Gobierno en 1871 por el comandante de corbeta "Chacabuco", don Enrique M. Simpson. Anales de la Universidad. Santiago, Chile, 389-431.

Simpson, E. (1874). Cuarto viaje de la comisión esploradora de la costa occidental de la Patagonia i de los archipiélagos de los Chonos i Guaitecas, practicado por orden del supremo Gobierno en 1871 por el comandante de corbeta "Chacabuco", don Enrique Simpson. Anales de la Universidad. Santiago, Chile, 505-558.

Steffen, H. (1910). Viajes de esploracion i estudio en la Patagonia Occidental 1892-1902. Santiago: Imprenta Cervantes.

Schwarzenberg, J., \& Mutizábal, A. (1929). Monografía geográfica e histórica del archipiélago de Chiloé. Concepción, Chile: Wissenschaftliches Archiv von Chile.

Torrejón, F., Bizama, G., Araneda, A., Aguayo, M., Bertrand, S., \& Urrutia, R. (2013). Descifrando la historia ambiental de los Archipiélagos de Aysen, Chile: El influjo colonial y la explotación económica -mercantil republicana (Siglo XVI-XIX). Magallania, 41(1), 2952.

Vea, A. (1886). Relación diaria del viaje que se ha hecho a las costas del estrecho de Magallanes con recelo de enemigos de Europa por don Antonio de Vea (16751676). Anuario Hidrográfico de la Marina de Chile. XI, 539-596.

Vidal, F. (1905). Estudios Geográficos e hidrográficos. Santiago: Imprenta Cervantes.

Urbina, R. (1988). Los Chonos en Chiloé: Itinerario y aculturación. Chiloé, 9, 29-42.

Urbina, R. (2007). El Pueblo Chono: de vagabundo a pagano alzado a cristiano sedentario amestizado. Universidad de Huelva , Orbis incognitus, I, 325-346.

Zusman, P. (2013). La Geografía Histórica, la imaginación y los imaginarios geográficos. Revista de Geografía Norte Grande, 54, 51-66.

Periódicos:

El Chilote (1878, Agosto 04) Ancud, Chiloé.

El Archipiélago (1888, Noviembre 11). Ancud, Chiloé.

El Católico (1888, Junio 07). Ancud, Chiloé.

La Cruz del Sur (1901, Marzo 16). Ancud, Chiloé.

La Probidad (1886, Abril). Ancud, Chiloé.

El Divisadero (2008, Noviembre 11). Los reyes del ciprés: el alemán Westhoff y el chonchino Alvarez. Consultado desde http://www.eldivisadero.cl/noticia-22783. 